\title{
WestVirginiaUniversity
}

THE RESEARCH REPOSITORY @ WVU

Graduate Theses, Dissertations, and Problem Reports

2006

\section{Updating low-profile FRP deck FE model using experimental modal analysis}

Srinivas Aluri

West Virginia University

Follow this and additional works at: https://researchrepository.wvu.edu/etd

\section{Recommended Citation}

Aluri, Srinivas, "Updating low-profile FRP deck FE model using experimental modal analysis" (2006). Graduate Theses, Dissertations, and Problem Reports. 1692.

https://researchrepository.wvu.edu/etd/1692

This Thesis is protected by copyright and/or related rights. It has been brought to you by the The Research Repository @ WVU with permission from the rights-holder(s). You are free to use this Thesis in any way that is permitted by the copyright and related rights legislation that applies to your use. For other uses you must obtain permission from the rights-holder(s) directly, unless additional rights are indicated by a Creative Commons license in the record and/ or on the work itself. This Thesis has been accepted for inclusion in WVU Graduate Theses, Dissertations, and Problem Reports collection by an authorized administrator of The Research Repository @ WVU. For more information, please contact researchrepository@mail.wvu.edu. 


\title{
UPDATING LOW-PROFILE FRP DECK FE MODEL USING EXPERIMENTAL MODAL ANALYSIS
}

\author{
Srinivas Aluri
}

Thesis submitted to the College of Engineering and Mineral Resources at West Virginia University in partial fulfillment of the requirements for the degree of

\author{
Master of Science \\ in \\ Mechanical Engineering
}

\author{
Jacky Prucz, Ph.D., Chairman \\ Hota V.S. GangaRao, Ph.D., Research Advisor, \\ Kenneth H. Means, Ph.D
}

Morgantown, West Virginia

2006

KEYWORDS: FRP Decks, Vibration, Modal Analysis 


\section{ABSTRACT \\ UPDATING LOW-PROFILE FRP DECK FE MODEL USING EXPERIMENTAL MODAL ANALYSIS}

\section{Srinivas Aluri}

A FRP composite cargo trailer was developed for the U.S. Marine Corps using the existing Prodeck4 FRP bridge deck as a trailer bed. Detailed finite element analysis and experimental evaluation was carried out on the FRP trailer. The FRP deck used is a new system and has orthotropic material properties, therefore an FE model of deck that is validated through experimental data will ensure confidence in results obtained from the FE model. Experimental modal analysis (EMA) was used to verify and update the FE model of the FRP deck.

A FE model of FRP deck was built in ANSYS® and the frequencies and mode shapes of the deck were evaluated. The FE model results were used in planning the modal tests to determine the best impact, best suspension, and the best accelerometer locations. The test setup was designed for the FRP deck based on the test planning results. Single input single output test was conducted on the FRP deck using an impact hammer and an accelerometer. Appropriate signal processing was performed, using LabVIEW VIs written for this purpose, on the acquired data to obtain the Frequency Response Functions (FRFs) for 112 FRF deck locations. A global curve fitting method known as 'Rational Fraction Polynomial' method was applied to extract the frequencies, mode shapes, and modal damping from the FRFs.

The various modes of vibration of FRP deck obtained from FE and EMA were correlated using Modal Assurance Criteria (MAC). The frequencies of correlated mode pairs of FE and EMA were compared and it was found that the difference was in the range of $\sim 26-40 \%$. Visual observation of the mode shapes of both FE and EMA revealed that the transverse stiffness and torsional stiffness of the FRP deck used in FE was lower than the actual FRP deck, thereby leading to lower frequencies in FE model when compared to correlated mode pair in EMA. The stiffness values, joint thicknesses were updated based on static test results and visual observation and the modal analysis was repeated including realistic boundary conditions on the FE model of the FRP deck. Comparison of results from FE model and EMA revealed a much better correlation of frequencies with a reduced error range of $\sim 1-5 \%$. The FE model does not predict two additional modes of the FRP deck (obtained through EMA). 
The frequencies and mode shapes of first two modes of vibration in FE and EMA have excellent correlation. Few other modes of FE and EMA also correlate well, however, the FE model does not predict two modes of vibration of the FRP deck. The updated FE model can be used to predict the dynamic response of the FRP deck in all cases where the response is dominated by the first two modes of vibrations. 


\section{ACKNOWLEDGEMENTS}

I wish to thank Dr. Prucz for his willingness to chair this thesis committee and for his advice in selecting the coursework, reviewing the thesis and for his comments and suggestions.

I am grateful to my research advisor Dr. Hota for facilitating the completion of my Master's degree in Mechanical Engineering while working full time with the Constructed Facilities Center. I am always inspired by his penchant for research and this thesis is evidence of that attitude, because work performed under this thesis is out of scope of the contractual obligations with the project sponsor. I would like to thank Dr. Means for serving on the committee and for reviewing and offering his comments on this work.

I sincerely appreciate the efforts of Jerry Nestor, Bill Comstock, Aneesh Bethi, and Ayman Bataineh during the testing of the FRP deck. Thanks are also due to ICATS, UK and Dr. Imregun for allowing me to evaluate the MODENT software suite for modal test planning, modal analysis, and modal correlation and granting permission to use the results obtained using the evaluation software in this report. I also wish to thank Mr. Gary Marraccini of Spectral Dynamics for arranging for the evaluation of the Siglab data acquisition system, which was used to test the FRP deck. 


\section{TABLE OF CONTENTS}

ABSTRACT …

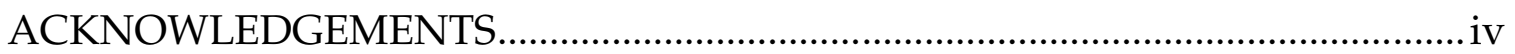

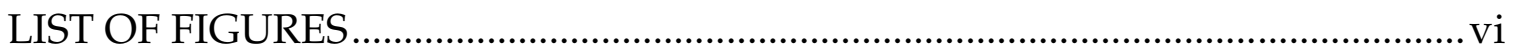

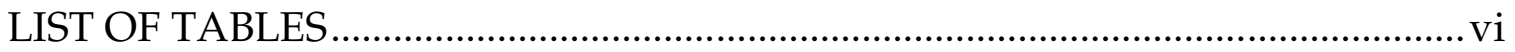

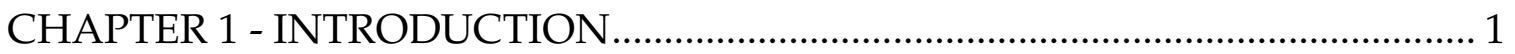

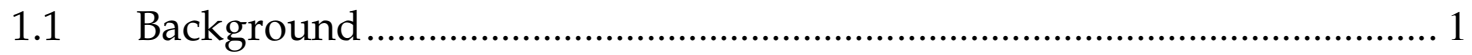

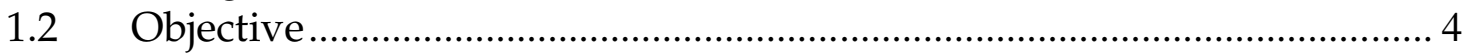

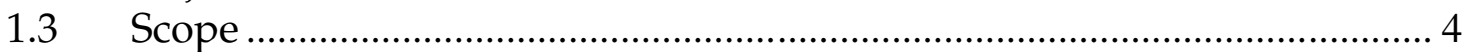

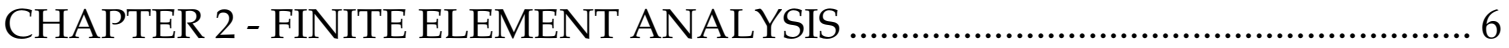

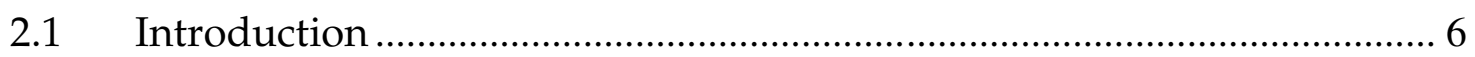

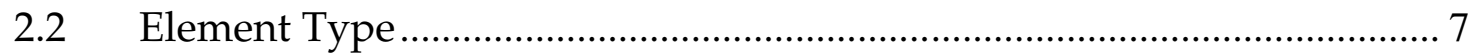

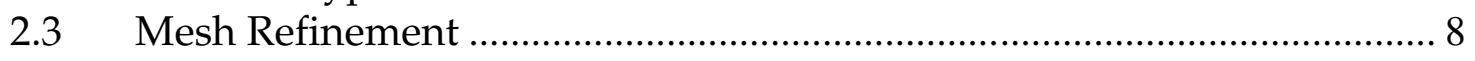

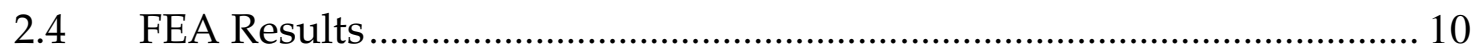

CHAPTER 3- TEST PLANNING AND SETUP ………………………………..... 13

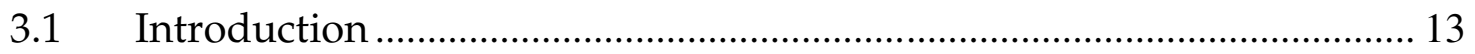

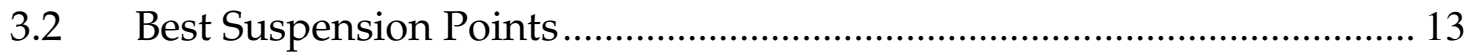

3.3 Best Impact Excitation Points ................................................................... 17

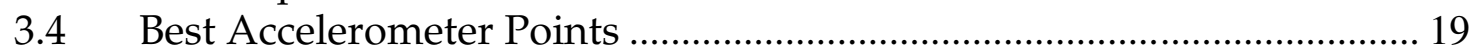

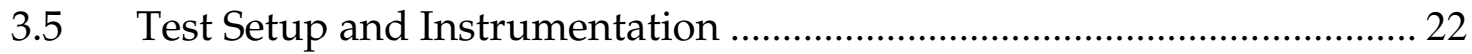

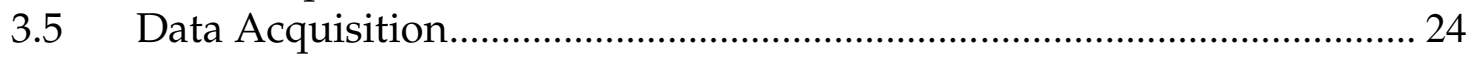

CHAPTER 4 - POST PROCESSING AND MODAL ANALYSIS OF TEST DATA

4.1 Post Processing of Test Data..................................................... 28

4.1 Basic Assumptions of Modal Analysis ................................................. 30

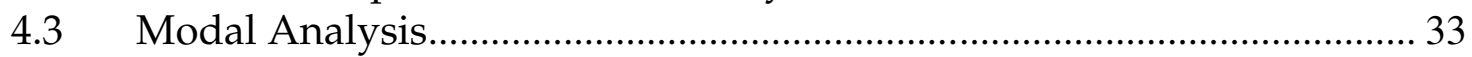

CHAPTER 5 - CORRELATION OF FE AND EMA RESULTS …………............. 42

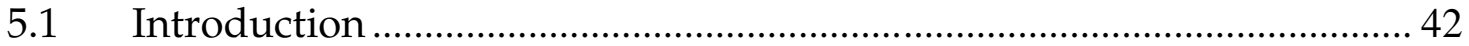

5.2 Comparison of Natural Frequencies …………....................................... 42

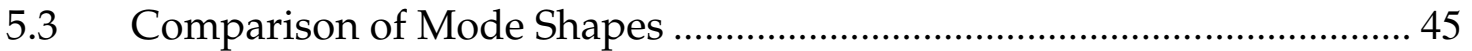

$5.4 \quad$ Updating the FE model ............................................................................. 48

5.5 Frequency Comparison- Updated FE vs. Experimental Results............. 52 CHAPTER 6 - SUMMARY AND CONCLUSIONS............................................... 56

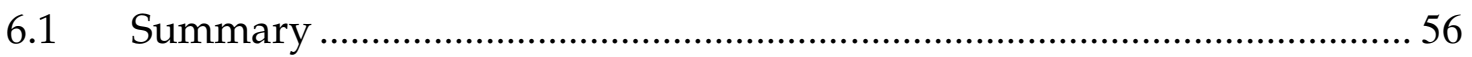

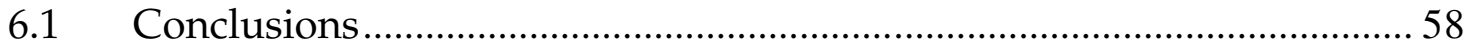

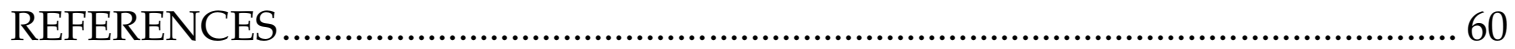

APPENDIX A - LabVIEW Program Descriptions ………………………….............. 62

APPENDIX B - CORRELATED MODE PAIRS ..................................................... 72 


\section{LIST OF FIGURES}

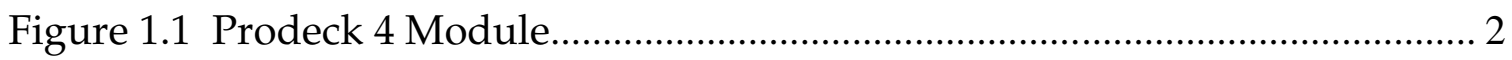

Figure 1.2 Proposed MTVR-T Design ............................................................... 3

Figure 2.1 Cross Section of the Full Deck Arrangement.................................................. 6

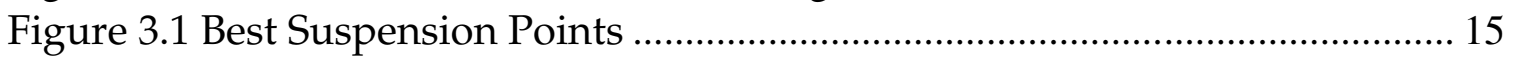

Figure 3.2 Actual Suspension Locations ……………........................................... 16

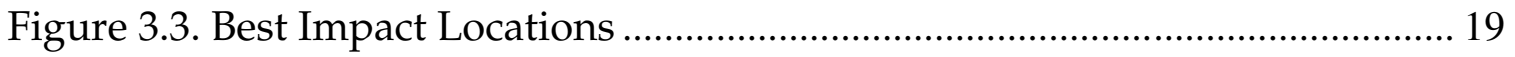

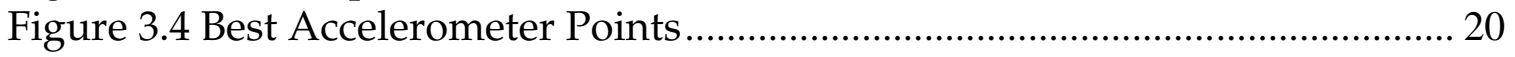

Figure 3.5 Test Setup of FRP Deck....................................................................... 23

Figure 3.6 Screenshot from Siglab ${ }^{\mathrm{TM}}$ Data Acquisition Software............................ 26

Figure 3.7 Measurement Locations............................................................................ 27

Figure 5.1 Modal Frequency Comparison and MAC .............................................. 44

Figure 5.2 Comparison of FE vs. Exp Modeshapes -Mode 1 .................................. 46

Figure 5.3 Comparison of FE vs. Exp Modeshapes -Mode 2 ….............................. 47

Figure 5.4 Modified FRP deck properties used in FE model.................................... 50

Figure 5.5 Material properties used to model the lap joints .................................... 51

Figure 5.6 Mesh of modified FE model for FRP Deck ............................................ 52

Figure 5.7 Second Mode, a) Updated FE - 22.49 Hz, b) Exp - 22.79 Hz .............. 53

\section{LIST OF TABLES}

Table 4.1. Frequencies of FRP Deck extracted using Circle Fit Method..............35

Table 5.1 Experimental vs. FE Frequencies......................................43

Table 5.2 Frequency Comparison between Correlated Mode Pairs................45

Table 5.3 Frequency Comparison between Correlated Mode Pairs of Updated FE

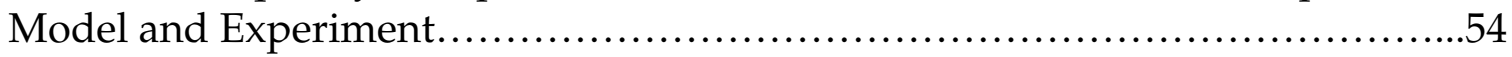




\section{CHAPTER 1 - INTRODUCTION}

\subsection{Background}

Fiber reinforced polymer (FRP) composites are finding increasing use in structural and bridge infrastructures. Bridge decks are one area where the advantages of FRP composites can be fully utilized. Constructed Facilities Center (CFC) at West Virginia University has been in the forefront in developing FRP composite bridge decks and along with West Virginia Department of Transportation and Federal Highway Administration was instrumental in building several FRP deck bridges in the state of West Virginia.

First generation FRP deck (Trade name - Superdeck ${ }^{\mathrm{TM}}$ ) developed at West Virginia University was made with E-glass fabrics and vinylester resin weighing about $22 \mathrm{lb} / \mathrm{ft}^{2}$. The self weight of the first generation deck was only about $1 / 6^{\text {th }}$ of comparable 8 " reinforced concrete deck. However, there was a need to reduce the weight of the deck further to make the FRP bridge decks cost-competitive with conventional bridge deck materials.

Working towards the goal of reducing FRP deck costs, CFC developed a low profile FRP bridge deck which has a self weight of $11 \mathrm{lb} / \mathrm{ft}^{2}$. The low profile deck is being manufactured by Bedford Reinforced Plastic Inc., PA and commercially 
sold as Prodeck 4 (Figure 1.1). Prodeck 4 is built using E-glass fabrics and vinylester resin using the pultrusion process. It is designed primarily as bridge deck to carry AASHTO HS-25 loading for $4 \mathrm{ft}$ stringer spacing.

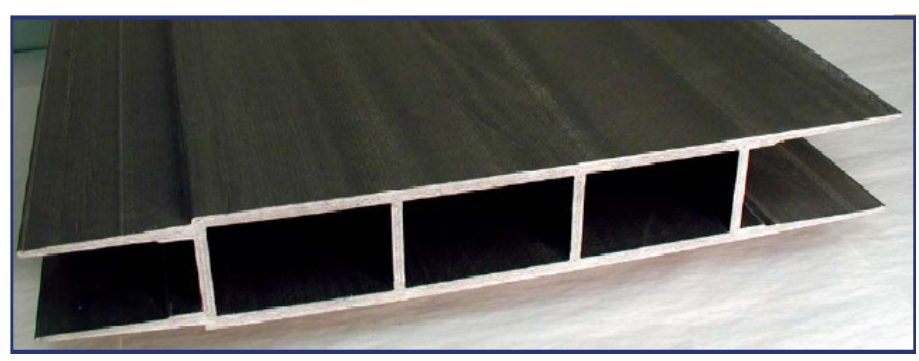

Figure 1.1 Prodeck 4 Module

Prior to installing Prodeck 4 on bridges, extensive static and fatigue tests were conducted on deck modules and decks [1], [2], [3] to evaluate its strength, stiffness and durability.

In 2004, Constructed Facilities Center along with Systems \& Electronics Inc, a full service supplier of defense products and supplies to U.S. Military, have started developing a FRP composite cargo trailer for the Medium Tactical Vehicle Replacement (MTVR). The proposed trailer a.k.a. MTVR-T will replace the current M105, M149 and M353 trailers. Figure 2 illustrates the initial design of the MTVR-T as proposed by SEI, Inc. 


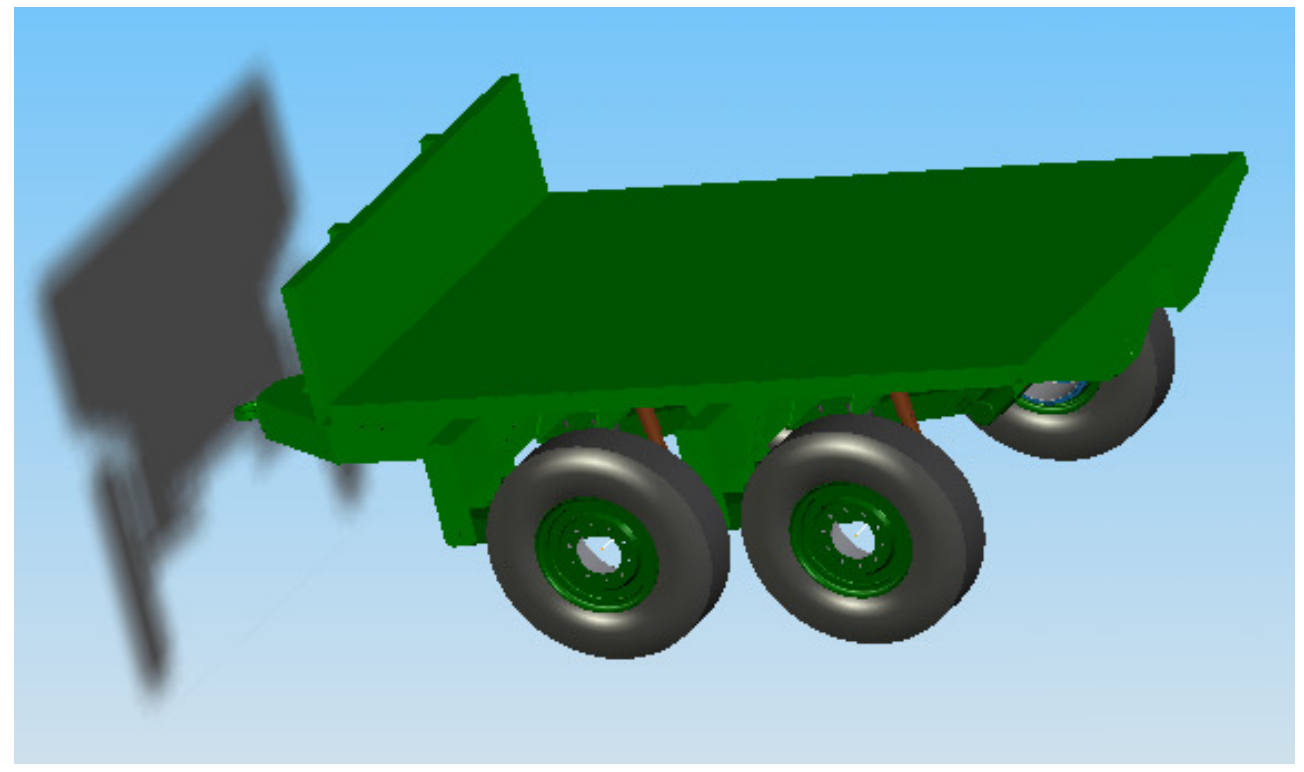

Figure 1.2 Proposed MTVR-T Design

CFC proposed to use the Prodeck 4 as a decking system for the MTVR-T instead of developing a completely new decking system, which would entail exorbitant development, tooling and manufacturing costs.

The initial task in the development of the trailer involved building a finite element (FE) model in ANSYS ${ }^{\circledR}$ of the FRP deck and the support assembly. The FE model will be used to perform stress analysis on the trailer for different load cases. The Prodeck 4 module is a new system and has orthotropic material properties, therefore an FE model that is validated through experimental data will ensure confidence in results obtained from the FE model. Experimental modal analysis (EMA) can be an effective tool in validating the FE model. EMA 
has three different stages: 1) test planning, 2) testing and post-processing of data, and 3) modal analysis (or curve fitting) of any structure. The modal parameters (frequencies, mode shapes, and damping ratios) are obtained from any EMA, which can be compared to the corresponding modal parameters obtained using FE analysis.

\subsection{Objective}

The objective of this research is to update the FE model using the experimental modal analysis data. Specifically the objectives are to:

1) Develop a FE model for Prodeck 4 and perform modal analysis to obtain the theoretical frequencies and mode shapes.

2) Conduct a modal test on Prodeck 4 and extract the frequencies, mode shapes and damping from the test data using curve fitting.

3) Update the FE model to reduce the "error" between FE results and EMA results.

\subsection{Scope}

A FE model for Prodeck 4 will be built in ANSYS $^{\circledR}$ without the supporting assembly and modal analysis will be performed. The details of FE modeling and 
modal analysis will be discussed in Chapter 2. Test planning is important in acquiring good quality modal data and avoiding pitfalls in testing such as locating an accelerometer at or near node points of a few modes. The FE results can be used to properly plan the test setup including specimen suspension locations, best locations for impact hammer excitation and best locations for accelerometer. The details of the test planning and setup will be discussed in Chapter 3.

Modal test data acquired from any test specimen needs post processing using various signal processing techniques and thereafter application of a curve fitting method to extract the desired modal parameters. Chapter 4 will provide the details of signal processing and subsequent curve fitting (or modal analysis) of modal data. It will also provide some details of the programs written in LabVIEW for processing the data.

In Chapter 5, the FE and EMA results will be correlated and the discrepancies will be analyzed. This information will be used to update the FE model and modal analysis is repeated on the FE model to reduce the "error" between the FE and EMA results.

Finally, a summary of this study and recommendations for future work will be presented in Chapter 6. 


\section{CHAPTER 2 - FINITE ELEMENT ANALYSIS}

\subsection{Introduction}

A finite element model was built in ANSYS ${ }^{\circledR}$ for a 98" x 137.5" FRP deck. The deck was built up of six individual Prodeck 4 modules, each pultruded to a length of $98^{\prime \prime}$ to create a $98^{\prime \prime} \times 148.97^{\prime \prime}$ deck. The overhang top and bottom flanges were cut off from both end modules to attain the required dimensions of $98^{\prime \prime} \mathrm{x}$ 137.915" (Figure 2.1).

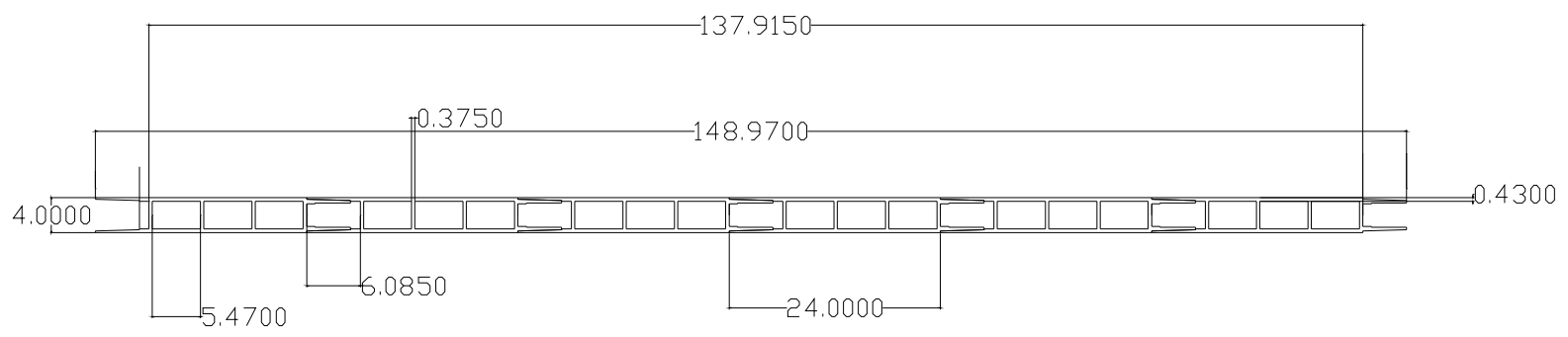

Figure 2.1 Cross Section of the Full Deck Arrangement

Each Prodeck 4 module is $\sim 29^{\prime \prime}$ wide and 4" deep with flange thickness being $0.43^{\prime \prime}$ and web thickness being $0.375^{\prime \prime}$. Modules are designed such that they fit into one another to form two lap joints at top and bottom flanges and are bonded together using Pliogrip ${ }^{\circledR}$ structural adhesive. In addition to the adhesive lap joints, the joint locations near the top and bottom of the deck are reinforced using E-glass fabrics and vinylester resin. This is done to ensure adequate force transfer 
between the two contiguous modules, since static tests on unreinforced transverse deck specimens have revealed inadequate force transfer [4].

\section{$2.2 \quad$ Element Type}

FRP composite structures are made up of thin laminates or plates, since thick composites result in failure due to delaminations between various layers.

Therefore, the composite structures can be modeled as thin plates using shell

elements. As mentioned above, Prodeck 4 consists of webs with $0.375^{\prime \prime}$ thickness and flanges with $0.43^{\prime \prime}$ thickness and is modeled as thin plates using SHELL 93 element available in ANSYS ${ }^{\circledR}$.

SHELL93 is an eight node structural shell with six degrees of freedom per node. The SHELL93 element is defined by eight nodes, four thicknesses and orthotropic material properties [5]. Figure 2.2 shows the geometry, node locations and the coordinate system for the SHELL93 element. The transverse shear stresses ( $\sigma_{\mathrm{yz}}$ and $\left.\sigma_{\mathrm{xz}}\right)$ are assumed to be constant through the thickness, this assumption is not valid for laminates that are thick and if the layers have very different shear properties [6]. 


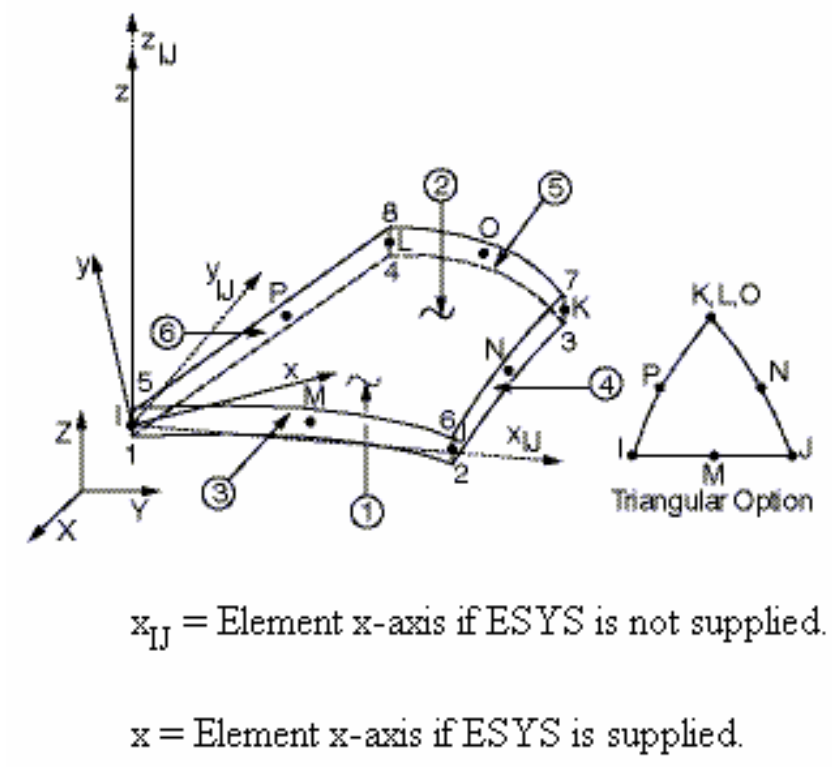

Figure 2.2 SHELL93 Geometry [5]

\subsection{Mesh Refinement}

In order to correlate the modal parameters obtained from FE models and EMA, the data points on a test structure should match with corresponding nodes in a FE model of the structure. With the availability of high powered computers, the FE models for structures can be finely meshed to get highly accurate values for frequencies and mode shapes. However, it is almost impossible to acquire data from the test structure at every node that is used in FE model. For this reason, it is prudent to keep the number of nodes in FE to a minimum without affecting the accuracy of results. 
To minimize the number of nodes in the FE model for Prodeck 4, two different mesh sizes were used to check for any significant changes in frequencies between the two models. This will help identify a reasonable mesh size from which enough test data points can be chosen to ensure a meaningful correlation.

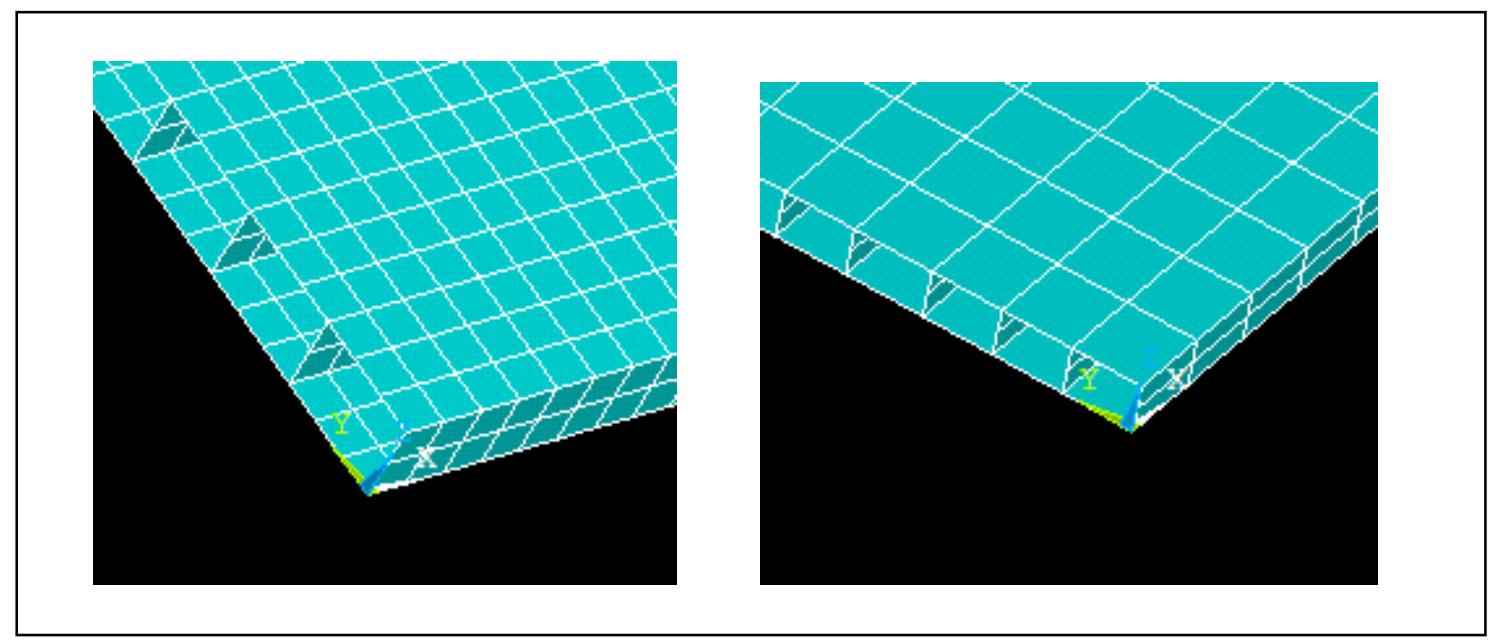
a) Fine Mesh
b) Coarse Mesh

Figure 2.3 Two Mesh Sizes

As shown in Figure 2.3 the fine mesh has 3 elements between the two webs and each element is two inch wide thereby having 49 elements along the $98^{\prime \prime}$ width of the trailer. The coarse mesh has only one element between the two webs and each element is seven inch wide thereby having 14 elements along the $98^{\prime \prime}$ width of trailer. Also, two elements were used along the depth of the flange in both cases, since one element did not yield satisfactory results. 
Modal analysis was performed for both the cases and it was found that the maximum difference in frequencies obtained from each model for any of the first eight modes was less than $0.85 \%$. The coarse mesh was deemed to be satisfactory in terms of accuracy and was chosen for test planning and further analysis.

\subsection{FEA Results}

The material properties used for Prodeck 4 were based on static load tests conducted at CFC [4] and are shown in Figure 2.4.
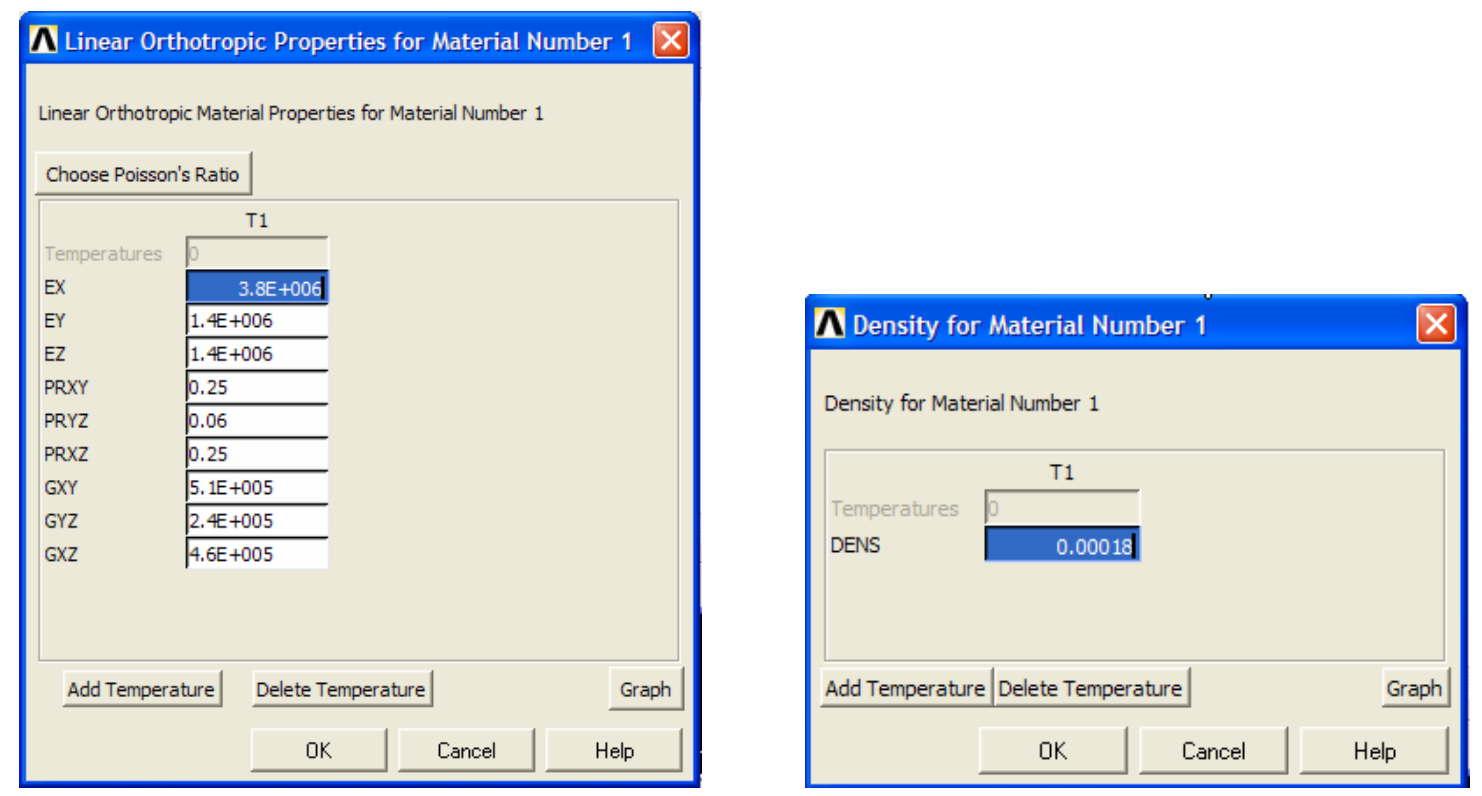

Figure 2.4 Material Properties of Prodeck 4

The model was analyzed without any boundary conditions since the test setup would also simulate a free support condition. Modal analysis was performed on 
the model using Block Lanczos mode extraction method and 20 modes were extracted and expanded. Since the model was analyzed without any constraints, the results will contain six rigid body modes which are numerically close to zero, hence the effective number of modes extracted is 14 . Figure 2.5 shows the frequency values for the first the 20 modes.

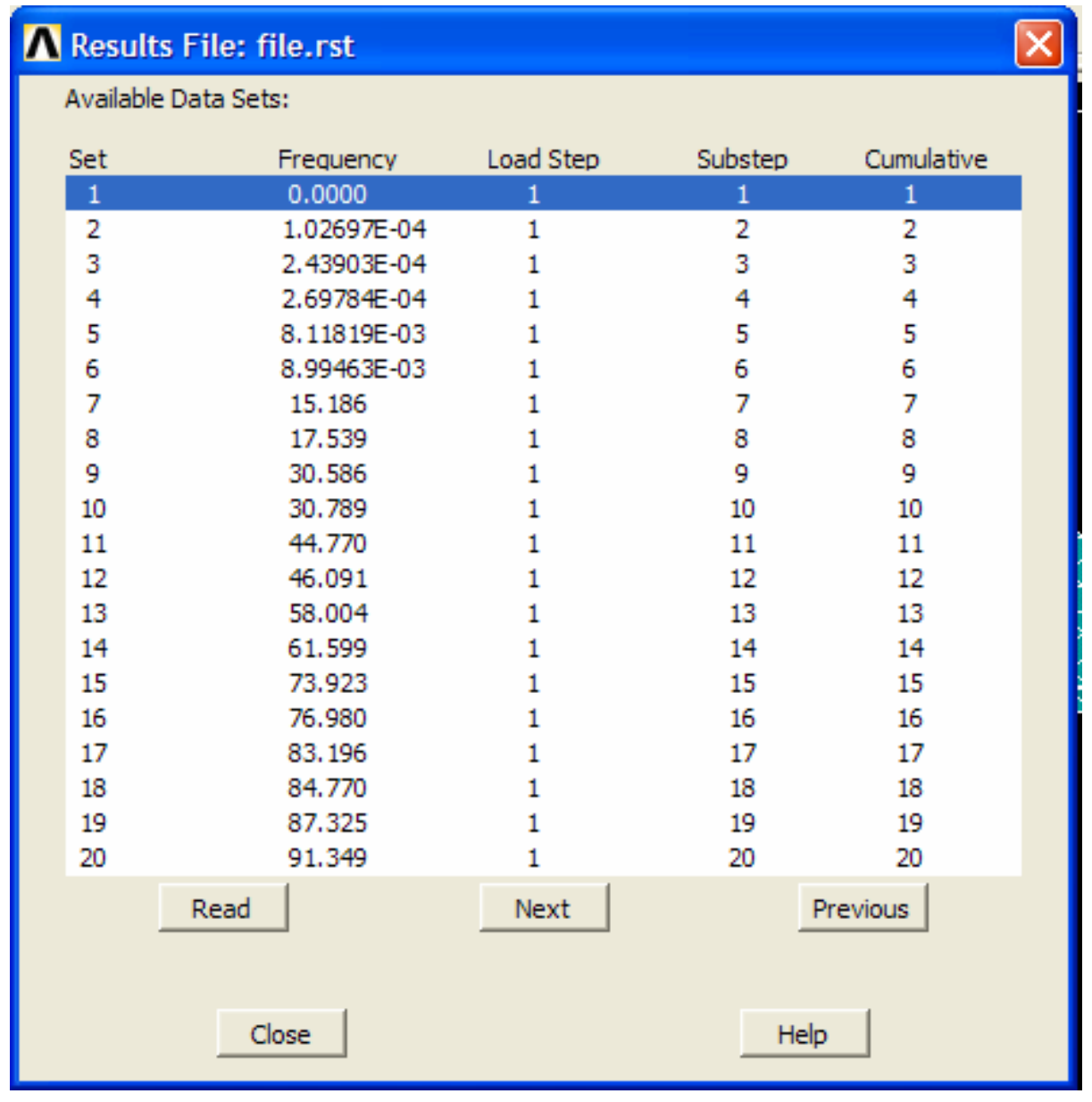

Figure 2.5 Frequency Results from Prodeck 4 FE Model 
The mode shapes for the frequencies listed in Figure 2.5 show that the first mode of vibration of Prodeck 4 is a torsional mode at $15.186 \mathrm{~Hz}$ and first three bending modes have a frequency of $17.539 \mathrm{~Hz}, 30.789 \mathrm{~Hz}$, and $44.77 \mathrm{~Hz}$. The various mode shapes obtained using FEA and comparison with experimental modes will be presented in Chapter 3 and in Appendix B. It should be noted that no damping was included in the FE model. 


\section{CHAPTER 3- TEST PLANNING AND SETUP}

\subsection{Introduction}

Proper test planning and setup are essential for acquiring accurate modal test data. Improper sensor location, support suspension location and excitation points can lead to incomplete modal data. Selection of accelerometer/excitation points is especially important for a single input single output (SISO) test because by locating the accelerometer near node locations of few modes, the response of those particular modes will not be captured. The test conducted on Prodeck 4 is a SISO test.

The results obtained from the FE Model of Prodeck 4 will be used to determine the best impact, best accelerometer and best suspension points. MODPLAN part of the modal analysis package MODENT Suite was used for test planning.

\subsection{Best Suspension Points}

As mentioned earlier, the test on FRP deck will be conducted using free-free boundary condition, since creating a constrained boundary condition that accurately replicates the boundary condition used in FE analysis is not possible. Theoretically any structure tested on free supports should have six rigid body modes, each of which has a frequency of $0 \mathrm{~Hz}$. Since in practice the free-free 
support is not truly free, the rigid body modes of the structure have frequencies which are over $0 \mathrm{~Hz}$. The free support condition can be used as long as the frequencies of rigid body modes are very low compared to the frequency of first structural mode, which was found to be the case for FRP trailer deck. 'Very low' means highest frequency of rigid body mode should be around $10-20 \%$ of the lowest bending mode [7].

The precautions that need to be taken to ensure minimal interference of suspension with the modes of vibration of the structure are [7]:

1) Suspension should be attached close to nodal points of modes of interest.

2) Possibility of suspension adding damping to a lightly damped structure.

3) Suspension wires/cables should generally be perpendicular to the primary direction of vibration.

The mode shape information obtained from FE analysis of FRP deck is used to determine the best suspension locations for the modes of interest. The optimum suspension location is where the total response (sum of amplitudes) of all the modes would be zero; in practice it may be difficult to find such a location. Therefore, the location which has the minimum total response of all the modes is ideal for a free-free boundary condition. 
The optimum suspension points are found where the average displacement for all modes is the lowest. The average displacement can be found by a parameter known as 'Average Driving DOF Displacement' or ADDOFD which is defined as [8]:

$$
\operatorname{ADDOFD}(j)=\sum_{r=1}^{m} \frac{\phi_{j, r}^{2}}{\omega_{r}^{2}}
$$

where $\mathrm{j}$ is location of DOF on the structure and $\mathrm{m}$ is the mode of vibration.

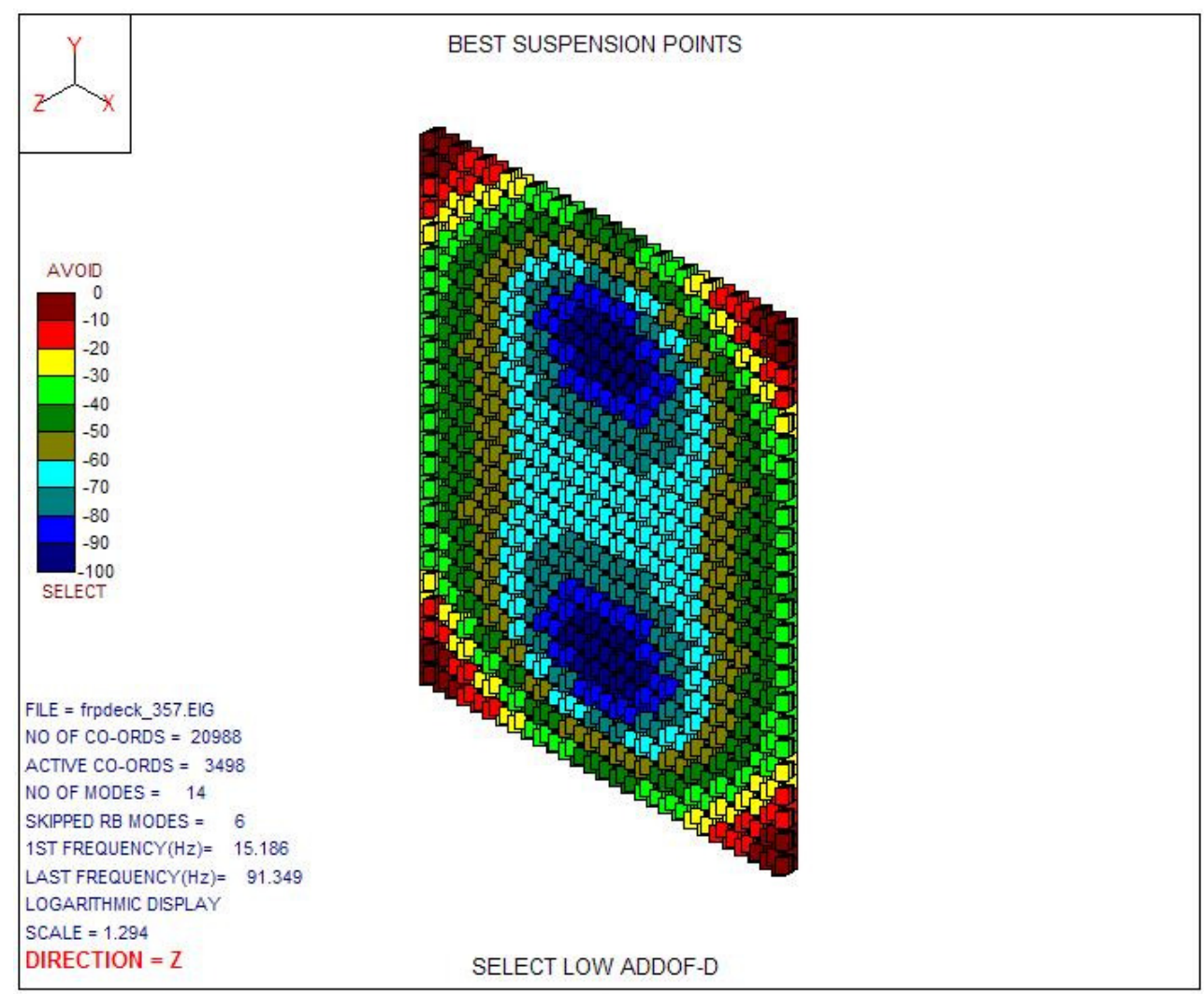

Figure 3.1 Best Suspension Points 
Figure 3.1 shows the contour plot of FRP deck with ADDOFD values, locations in dark blue are optimum suspension points. However, they were not chosen because suspending the deck at just two locations would make it unstable for testing. The four suspension locations chosen were $28-1 / 2^{\prime \prime}$ into the width of the deck and around 28-1/4" into the length of the deck (Figure 3.2). According to the scale used in Figure 3.1 the selected locations have a scaled ADDOFD of between -80 and -70 whereas the best locations are ones having a scaled ADDOFD of -100 .

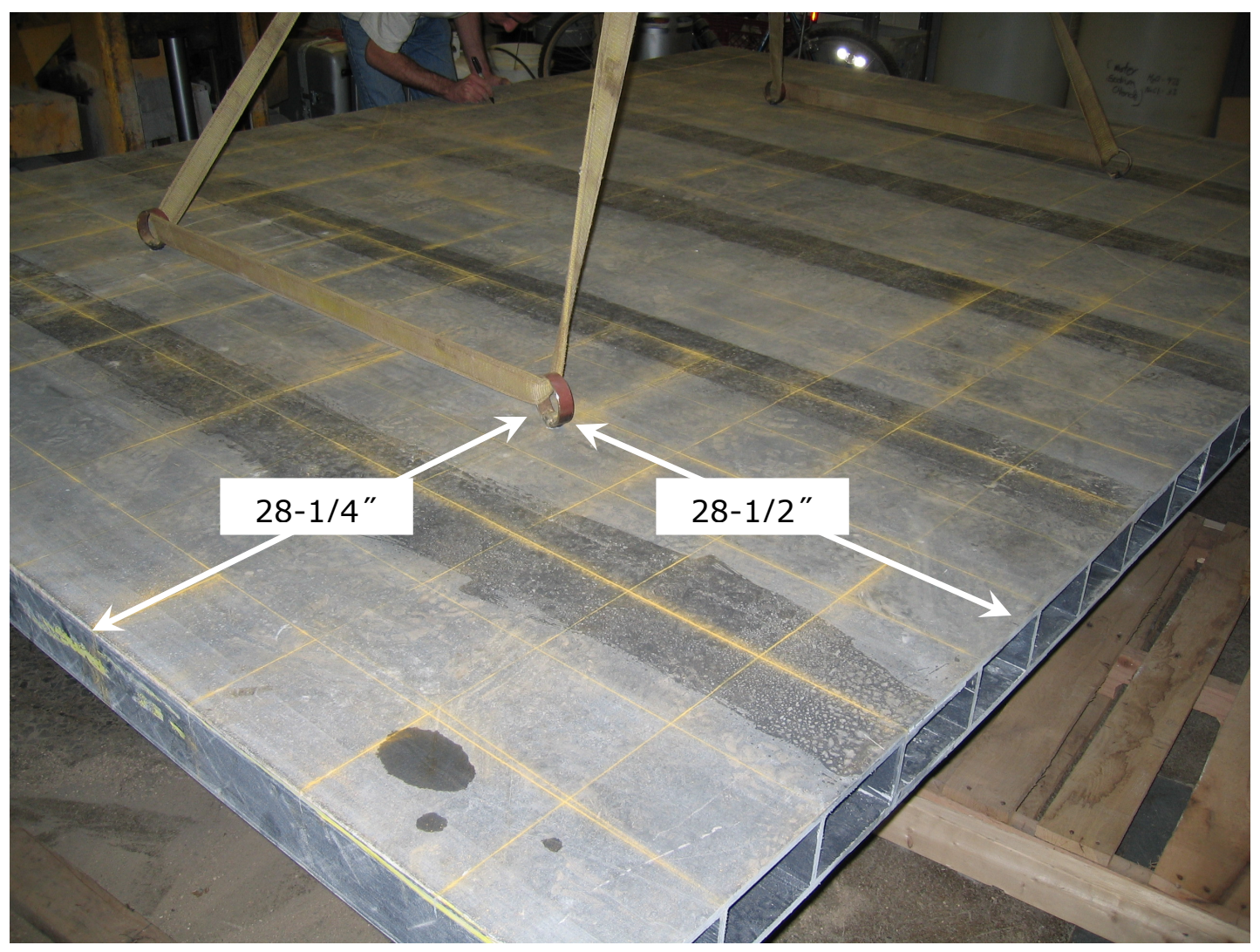

Figure 3.2 Actual Suspension Locations 


\subsection{Best Impact Excitation Points}

The locations for best impact are selected based on two criteria:

1) Avoiding the nodal lines of modes since there would be no energy transfer from the point of impact at node locations to all other DOFs of the structure.

2) Picking a location with low average velocity for all the modes will eliminate the problem of "double-hits" of impact hammer.

To avoid locations near the nodal lines of modes, Non-Optimum Driving Point (NODP) technique can be used. According to Imamovic [8], "the method defines a parameter for each DOF which describes how close that DOF is to a nodal line of any mode within a specified frequency range. The method selects the minimum absolute value of all modal constants for all selected modes for a DOF and defines that value as the NODP parameter for that DOF."

$$
\operatorname{NODP}(\mathrm{j})=\underset{r}{\operatorname{Min}}\left\{\left\|\phi_{j, r}\right\|\right\}
$$

A low value of NODP indicates the DOF is close to nodal lines for the selected modes. 
The problem of "double-hits" can be avoided by selecting locations with low average velocity. The average velocity can be found by a parameter known as 'Average Driving DOF Velocity' or ADDOFV which is defined as [8]:

$$
\operatorname{ADDOFV}(j)=\sum_{r=1}^{m} \frac{\phi_{j, r}^{2}}{\omega_{r}}
$$

where $\mathrm{j}$ is location of DOF on the structure and $\mathrm{m}$ is mode of vibration

A location with high ADDOFV should be avoided for impact hammer excitation to reduce the possibility of "double-hits". The best impact excitation location (or DOF) can therefore be chosen picking the DOF with high NODP/ADDOFV ratio (Figure 3.3). 


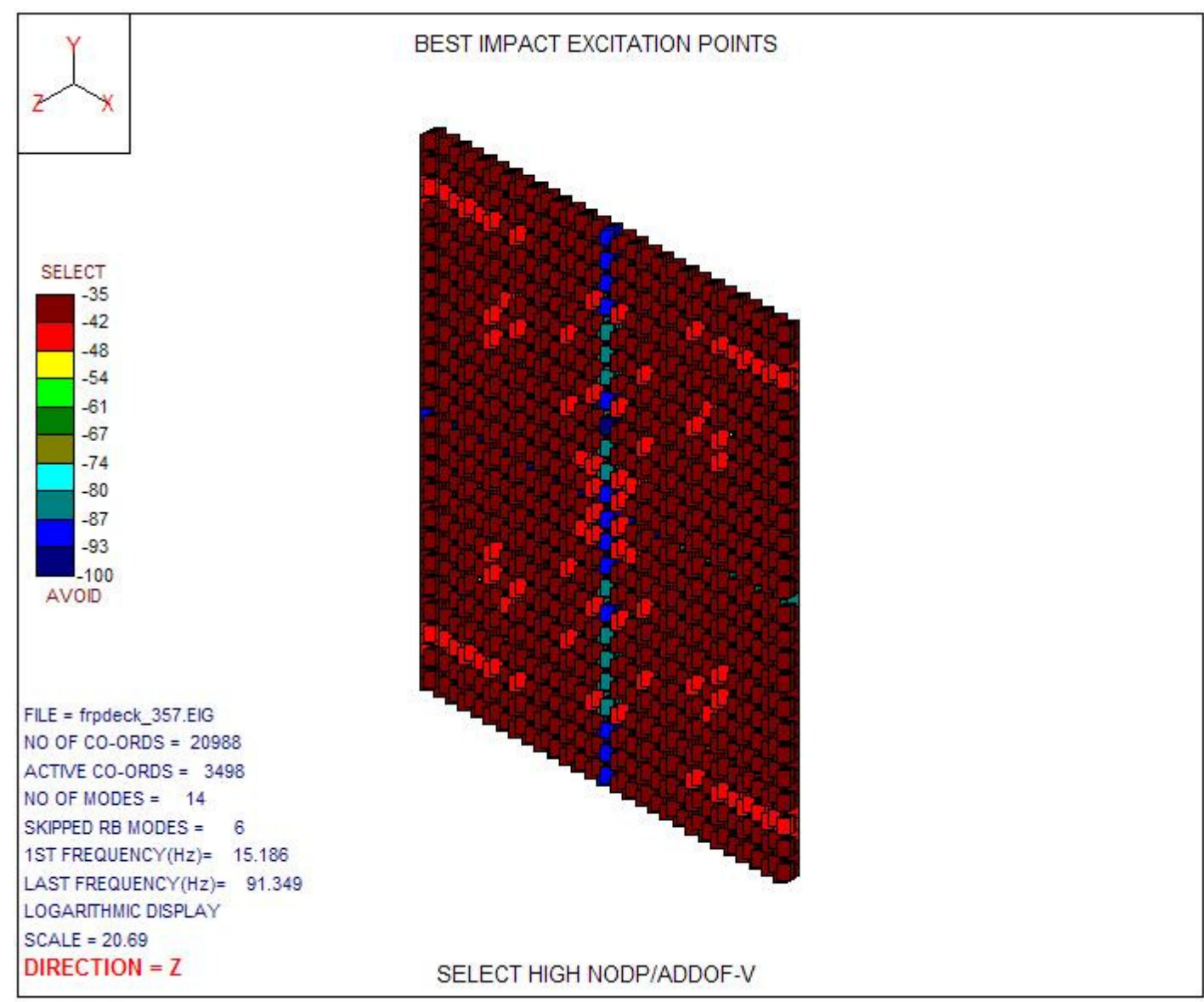

Figure 3.3. Best Impact Locations

\subsection{Best Accelerometer Points}

The best location of accelerometer is selected by the using the EI-ADDOFA

optimization method proposed by Imamovic [8], EI stands for Effective

Independence Matrix and ADDOFA stands for Average Driving DOF

Acceleration. The EI-ADDOFA method is a modification to the EI optimization method proposed by Kammer [9]. 


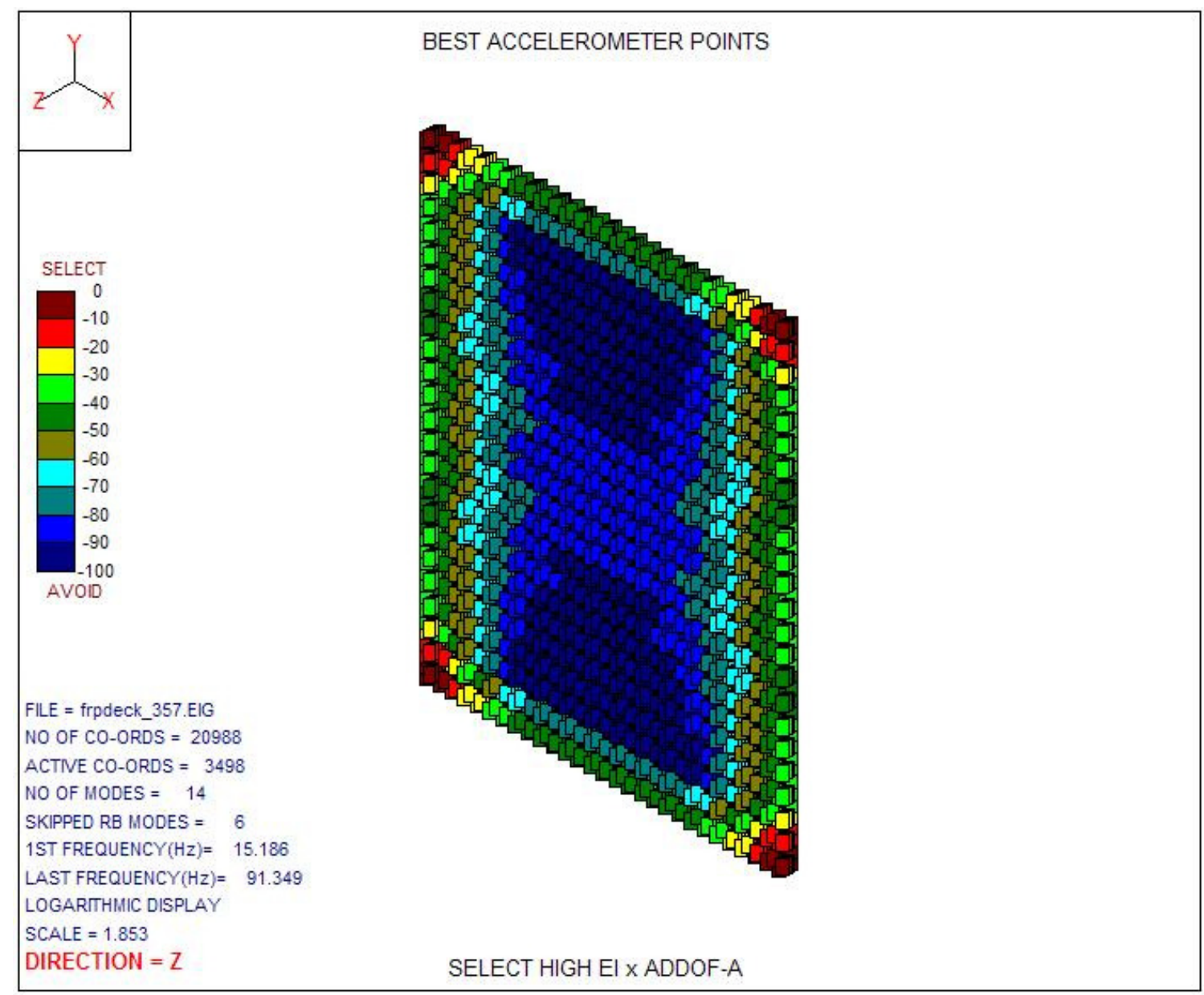

Figure 3.4 Best Accelerometer Points

The effective independence method starts out by calculating the so-called 'Prediction Matrix,' [E] for the mode shape matrix

$$
[E]_{N x N}=[\phi]_{N x m}\left([\phi]_{m x N}^{T}[\phi]_{N x m}\right)^{-1}[\phi]_{m x N}^{T}
$$

where $[\phi]_{N x m}$ is the mode shape matrix consisting of m modes evaluated at $\mathrm{N}$ DOFs. 
The Prediction Matrix is idempotent matrix $\left([E]^{m}=[E]\right)$, and it possesses some interesting properties.

$$
\operatorname{trace}[E]=\operatorname{rank}[E]=\operatorname{rank}[\phi]
$$

The goal of any modal test engineer is to obtain the modal parameters of a system especially mode shapes with fewest possible measurement locations, to reduce the time and cost of testing. Measurement locations should be chosen such that mode shapes are independent i.e., the columns of the $[\phi]$ must be linearly independent. Each of the diagonal terms of $[E]$ matrix indicates the contribution of that particular DOF to the rank of $[\phi]$. The smallest diagonal term of $[E]$ reveals the DOF which has least contribution to the linear independence of the mode shapes, this DOF is eliminated and the process is repeated until rank $[\phi]$ is less than the number of modes $m$ i.e., until $[\phi]$ ceases to be full rank.

The EI method is effective in picking the DOFs to ensure the linear independence of the mode shapes, but the method does not distinguish between DOFs with high or low response. DOFs with higher responses are preferred for better signal to noise ratio, and high response DOF can be identified by the parameter 'ADDOFA' which is defined as follows [8]:

$$
\operatorname{ADDOFA}(j)=\sum_{r=1}^{m} \phi_{j, r}^{2}
$$

where $\mathrm{j}$ is location of DOF on the structure and $\mathrm{m}$ is mode of vibration 
Imamovic [8] proposed a modification to the EI method called the ADDOFA-EI method, in this method the diagonal values of $[E]$ matrix are multiplied by their corresponding ADDOFA values and the same iterative procedure as the EI method is applied to determine the fewest number of measurements to ensure linear independence of mode shapes. By including the ADDOFA, the modified method picks DOFs with better response, apart from the linear independence requirement (Figure 3.4).

\subsection{Test Setup and Instrumentation}

The FRP deck was setup based on the extensive pre-test planning, as described in previous sections. Four eye-bolts were bolted to the FRP deck at four locations (shown in Figure 3.5), two cloth slings were used to suspend the deck. The two slings were attached to a chain using a hook, the chain was passed around the center beam of a load frame. The load frame has very high stiffness when compared to the stiffness of the deck and hence any minute vibrations of frame transmitted through the suspension would not fall into the frequency range of FRP deck modes. Ideally, the deck should be suspended using elastic cords or small air bags, but there are no commercially available elastic cords which can handle the weight of this FRP deck and small airbags, even if available, were not used because of cost reasons. 


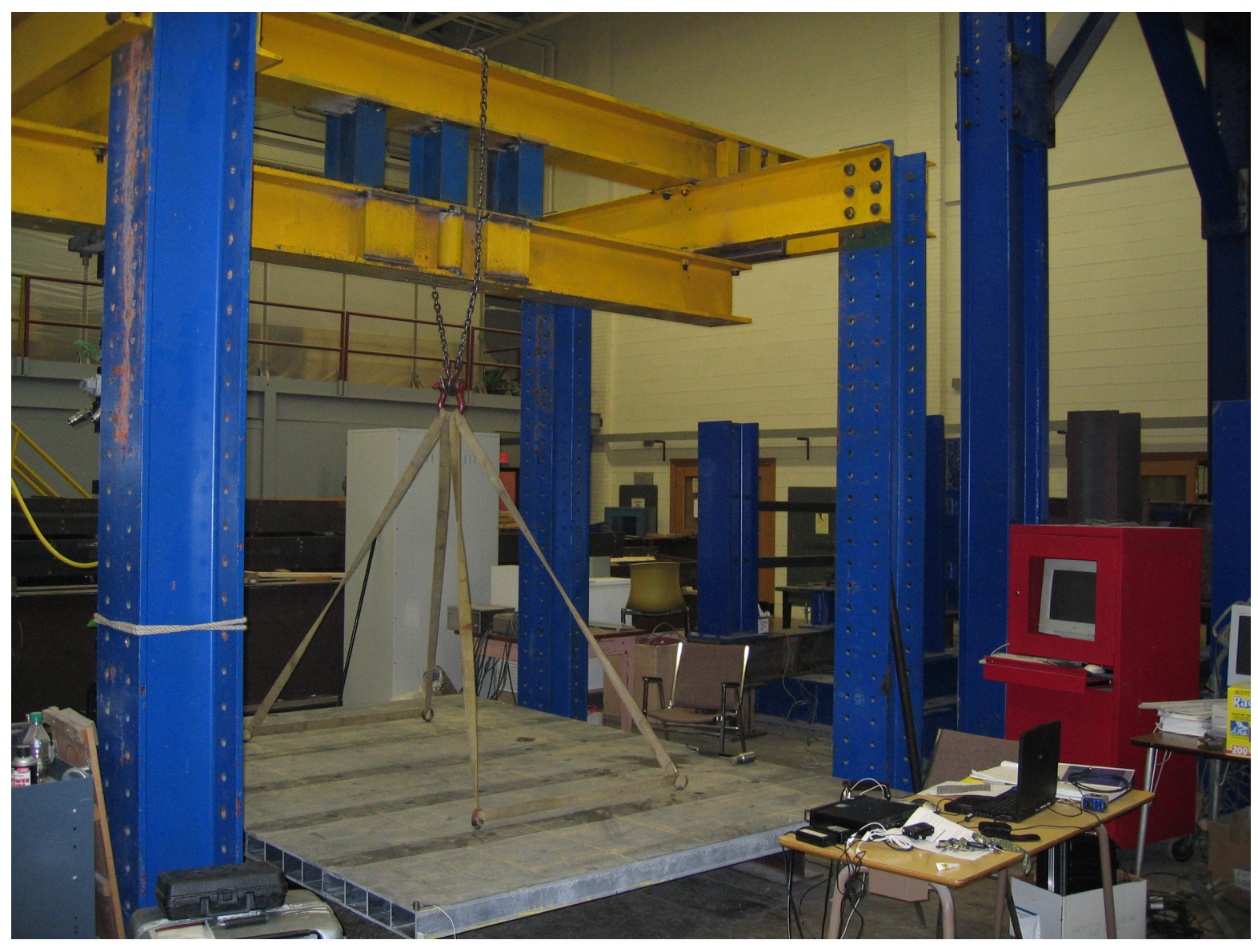

Figure 3.5 Test Setup of FRP Deck

The time allocated for modal testing was just two days, including setup and dismantling time, since the FRP deck was to be bonded to the subsystem to build a FRP trailer for static testing. Therefore, only one accelerometer could be calibrated and also impact hammer excitation was chosen, since setting up of electrodynamic shakers would be time consuming. SISO method of test was used because of time constraints. 
Based on the pre-test analysis of the best location for the accelerometer was at any of the corners of the FRP deck. PCB J353B33 accelerometer (Sensitivity 100 $\mathrm{mV} / \mathrm{g}$ and frequency range of $1-4000 \mathrm{~Hz}$ ) was used to acquire the response, the accelerometer was bonded to the FRP deck using "Super Glue." The accelerometer was calibrated using drop calibration method before and after the modal test.

The size of impact hammer should be chosen such that the hammer is heavy enough to impart enough energy into the structure to excite all the modes of interest without damaging the structure. A $5000 \mathrm{lbf}$ impact hammer (Kistler model 9728A20000) was used to excite the FRP deck, a soft tip was used to excite the deck, since the maximum frequency of excitation needed was only $200 \mathrm{~Hz}$. The impact hammer was received the day before the actual test and was calibrated by the manufacturer the previous day. Therefore, no calibration was performed on the impact hammer.

\subsection{Data Acquisition}

DSTP Siglab ${ }^{\text {TM }}$ Model 20-42, dynamic signal analyzer was used to acquire the data from the impact hammer and accelerometer. The 20-42 system has four input channels and two output channels. Each input channel is simultaneously sampled with sampling rate of $51.2 \mathrm{kHz}$ and has a separate 16 bit resolution 
Sigma-delta A/D convertor for each channel. Siglab ${ }^{\mathrm{TM}}$ is driven by MATLAB ${ }^{\circledR}$ based software, the software consists of several modules, each module is designed for a specific area such as structural dynamics, noise and vibration, rotating machinery analysis etc. The vna module in Siglab ${ }^{\mathrm{TM}}$ was used for testing the FRP deck and only time domain data was acquired although Siglab ${ }^{\mathrm{TM}}$ could perform all the required signal processing, and calculate frequency response functions (FRFs) directly.

A sampling rate of $1280 \mathrm{~Hz}$ was used and 4096 points were collected giving a frequency resolution of $0.3125 \mathrm{~Hz}$. In retrospect, it is found that sampling rate was on the higher side since modes over $350 \mathrm{~Hz}$ were not adequately excited due to the use of soft tip. The impact hammer and accelerometer were both connected to battery powered $\mathrm{ICP}^{\circledR}$ signal conditioners. Impact hammer was connected to channel 1 of the data acquisition system and its signal was used to trigger the data collection. The accelerometer was connected to channel 2. Figure 3.6 shows the screenshot of the vna module in Siglab ${ }^{\mathrm{TM}}$, window on the top shows the time history of impact hammer and bottom window shows the acceleration time history.

The threshold for trigger of impact hammer was set at $9 \%$ of peak value and a pre-trigger of -0.1 was chosen to completely acquire the impact signal. No 
windows were applied during acquisition to either the hammer input data or the accelerometer data.

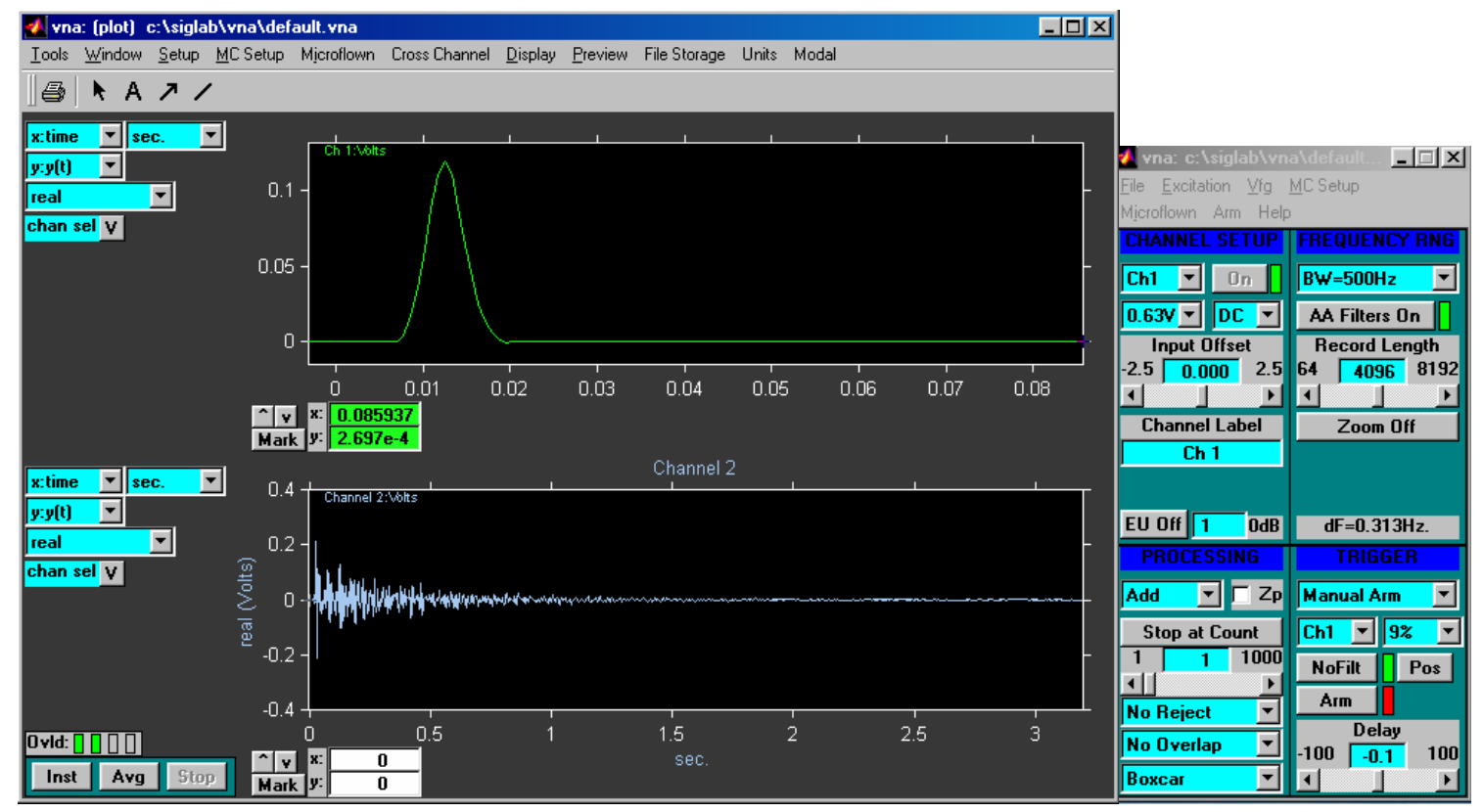

Figure 3.6 Screenshot from Siglab ${ }^{\mathrm{TM}}$ Data Acquisition Software

Single input single output (SISO) method was used for testing the FRP deck. The impact hammer was roved on different measurement points while the reference accelerometer was placed at location 3402 (Figure 3.7) on the deck. This type of test is called a roving hammer test. One hundred twelve (112) locations on the top of deck were chosen from FE mesh for excitation using impact hammer (Figure 3.7). 


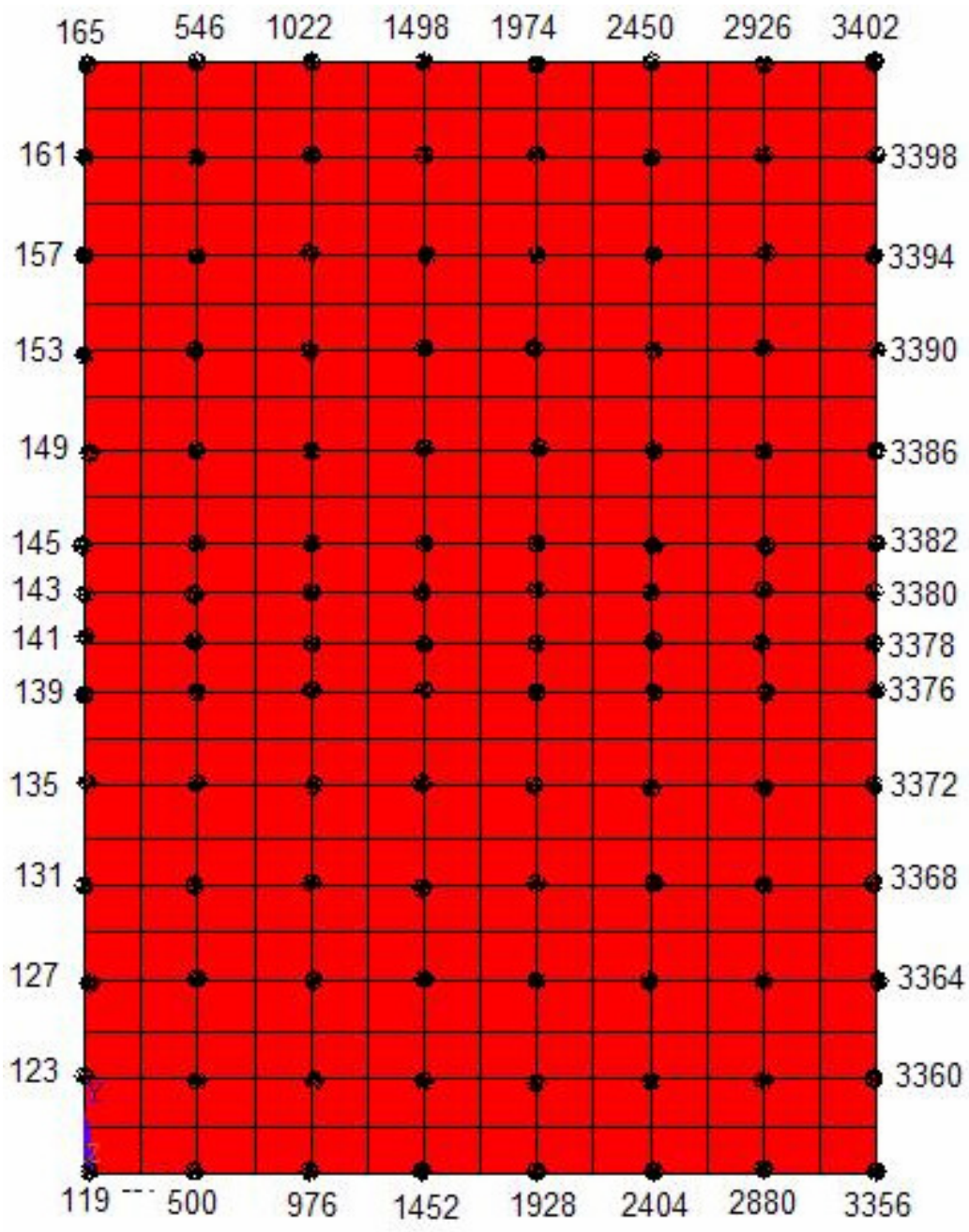

Figure 3.7 Measurement Locations

Test data collected as per the procedure described in this chapter has to be processed to calculate the frequency response functions. The post processing of the time domain data is described in detail in next chapter. 


\section{CHAPTER 4 - POST PROCESSING AND MODAL ANALYSIS OF TEST DATA}

\subsection{Post Processing of Test Data}

Time domain data acquired during a modal test has to be post-processed before evaluating the frequency response functions. Problems such as leakage, experimental noise, low frequency resolution, DC offsets can be reduced or eliminated during post processing. As mentioned in the earlier chapter, data was acquired at 112 locations on the FRP deck, and four sets of data were acquired at each point.

The first step in signal processing is to remove the DC offset from both the hammer and accelerometer signals. A typical hammer impulse signal should have a half-sine peak and a flat line, however the impulse signal is usually contaminated with noise. Since it is known that no force input has occurred after the half-sine peak, a rectangular window can be applied to the hammer excitation to zero all values of the signal after the half-sine peak, thereby eliminating noise from that part of the signal. The accelerometer signal is completely observable within the time of capture and no exponential window was needed. 
The frequency resolution obtained by calculating FRF directly from measured data is $0.3125 \mathrm{~Hz}$; however, the FE results reveal that FRP deck has several close modes, some of them are within the resolution of $0.3125 \mathrm{~Hz}$ e.g. $30.586 \mathrm{~Hz}$ and $30.789 \mathrm{~Hz}$. The frequency resolution of FRF was increased to $0.078125 \mathrm{~Hz}$ by adding 12,288 zeros to both hammer and accelerometer signals thereby increasing the total time of signals to 12.8 secs, this technique is known as 'zero padding'.

The FRF is calculated using $\mathrm{H}_{1}$ method, which is the ratio of Cross Power Spectrum between stimulus (impact hammer) and response (accelerometer) and Auto Power Spectrum of stimulus [10]. The FRFs were calculated for each of the four sets of data at each point and then averaged and this process is repeated for all 112 points.

The above signal processing was done using custom VIs (programs) written in LabVIEW, details of the VI are provided in Appendix A. For importing the FRFs into any commercially available Modal Analysis packages, the FRFs have to be converted to either the Universal File Format 58 (UFF58) or into a package specific format. LabVIEW VI's were written to format the FRFs into UFF58 specification. The UFF58 specification can be found at http://www.sdrl.uc.edu/uff/SDRChelp/LANG/English/unv_ug/UNV_0058.h $\underline{\mathrm{tm}}$. 


\subsection{Basic Assumptions of Modal Analysis}

Modal analysis can be applied to any structure as long as the structure satisfies the basic assumptions on which modal analysis is based on. The assumptions are as follows [11]:

1) The structure is linear, the magnitude of FRFs should not change due to variation in input force.

2) The structure can be considered time invariant i.e., the behavior of structure should not change with time.

3) The structure is observable, in other words the structural response should be measurable with sufficient sensors available to adequately describe the input-output characteristics of system.

4) The structure obeys Maxwell's reciprocity theorem, a frequency response function measured at location $p$ due to excitation at location $q$ should be the same as a frequency response function measured at location $q$ due to excitation at location $p$.

Linearity of FRP deck was verified by comparing the FRFs computed from two data sets at same location, since no two impact excitations impart the same force to the deck. Figure 4.1 shows the plot comparing the FRFs of two data sets (trial 1 
and trial 2) at location 1000 (Figure 3.7), it can be seen that there are identical without any change in amplitude levels.

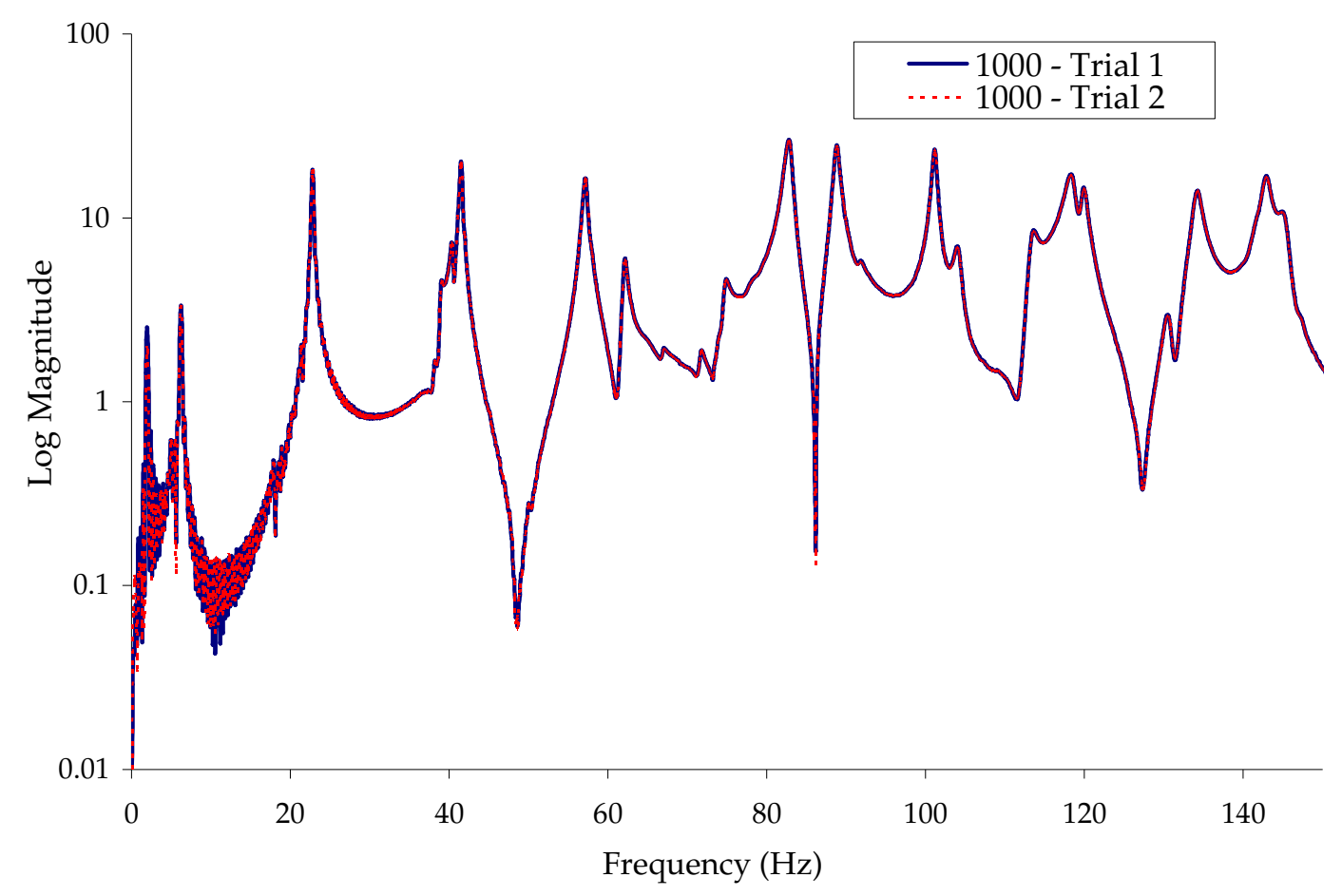

Figure 4.1 FRP Deck Checked for Linearity

Time invariance check was performed by acquiring the response at location 3402 and due to excitation at 2884 at different times of the days, first data acquisition was at 11.12 AM and next data acquisition was at 9.48 PM. A comparison of FRFs for these two data sets, shown in Figure 4.2, reveals that FRP deck response is time invariant (since temperature is constant in laboratory environment). Also, it 
is obvious from Figures 4.1 and 4.2 that the FRP deck response is observable, thereby satisfying the third condition mentioned above.

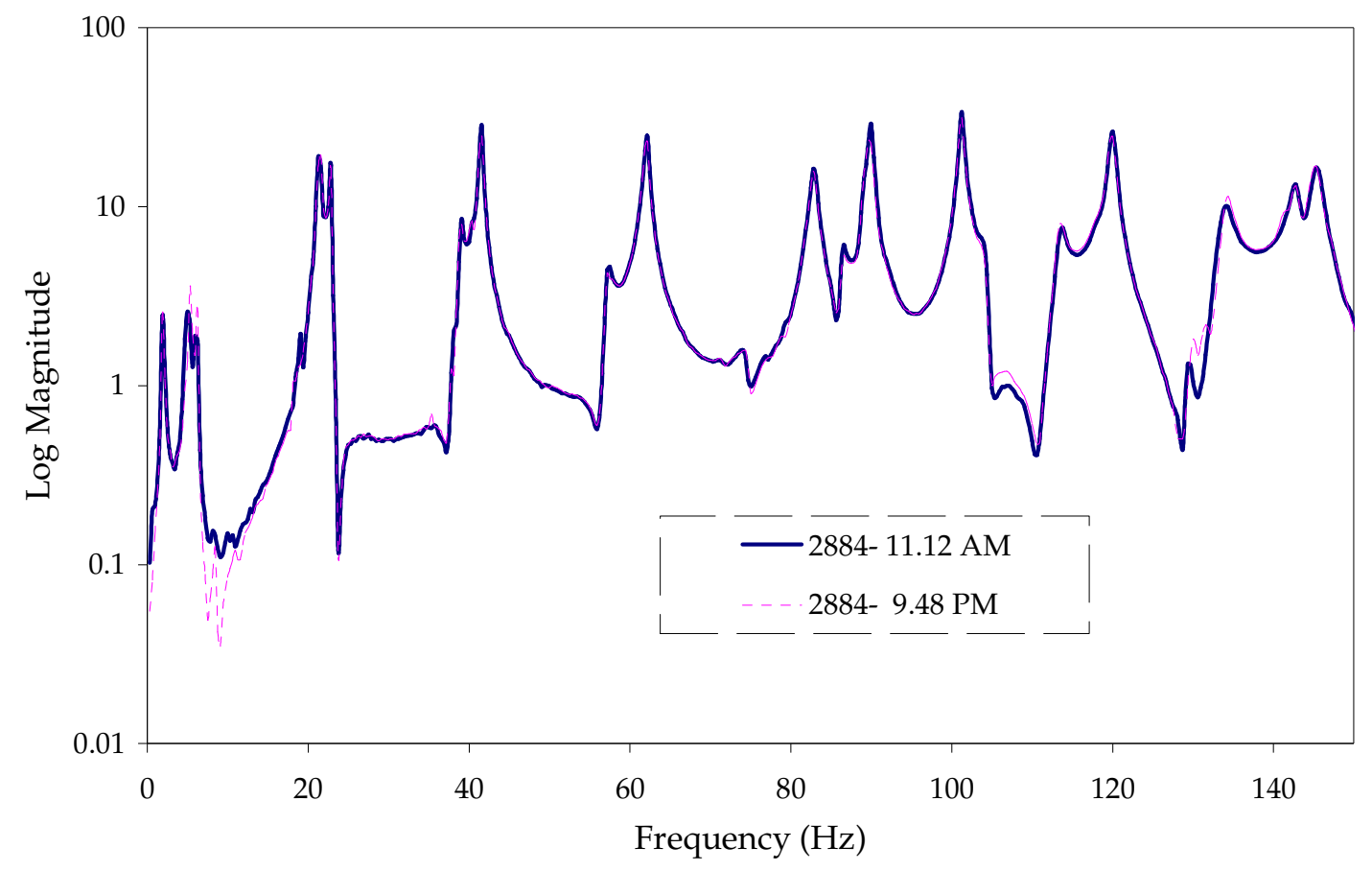

Figure 4.2 FRP Deck for Time Invariance

In order to verify that the FRP deck obeys Maxwell's reciprocity theorem, the response at location 3402 due to excitation at 1498 was acquired and the response at location 1498 due to excitation at 3402 were acquired and the FRFs were compared. Figure 4.3 shows that both the FRFs $\mathrm{H}_{3402,1498}$ and $\mathrm{H}_{1498,3402}$ are almost identical, thereby satisfying the Maxwell's reciprocity theorem. 


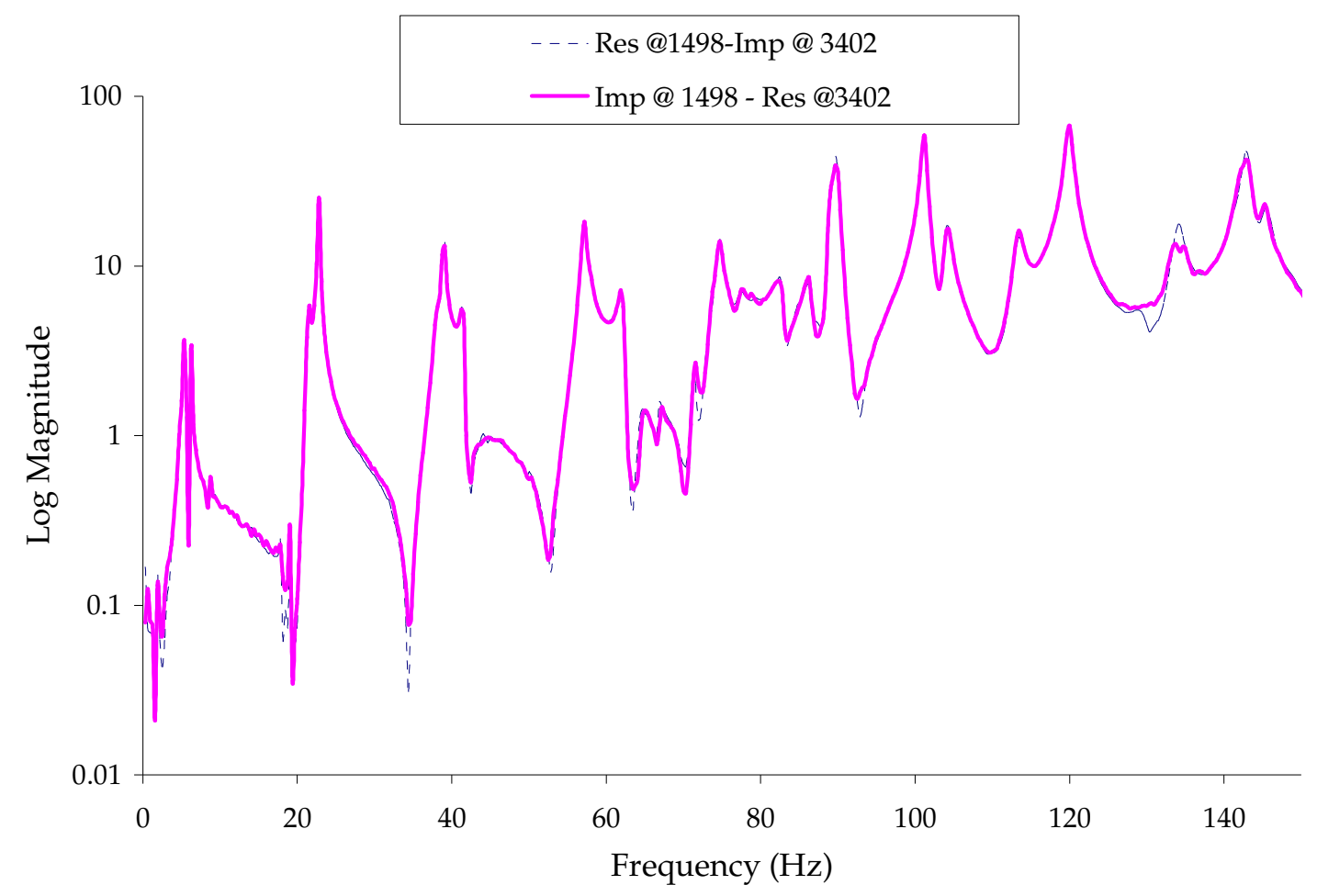

Figure 4.3 FRP Deck Check for Reciprocity

\subsection{Modal Analysis}

Modal analysis or modal parameter extraction methods can be broadly classified into frequency and time domain methods. Based on range of frequencies selected for each individual analysis, the frequency domain methods can be further classified into SDOF methods and MDOF methods. The methods can be also be classified into single FRF methods and multi FRF methods. The multi FRF 
methods are grouped into global methods (for Single Input Single Ouput (SISO) or Single Input Multiple Output (SIMO) data sets), and polyreference methods for Multiple Input Multiple Output data [7].

Peak-Amplitude method, Circle Fit method and Line Fit method are some of the Single DOF methods. SDOF methods extract the properties of one mode at a time on a single FRF and therefore are time consuming to apply to large sets of FRFs. However, the SDOF methods are very useful in providing initial estimates of frequency, identifying problems such as non-linearity etc and type of damping of system. The Circle Fit method was used to identify the different frequencies of FRP deck; the frequencies are listed in Table 4.1. The frequency estimates were useful in determining the frequency range for applying global modal analysis methods. Frequencies estimated from Circle Fit method on $\mathrm{H}_{3402,119}$ are listed in Table 4.1. 


\section{Table 4.1 Frequencies of FRP Deck extracted using Circle Fit Method}

\begin{tabular}{|c|c|}
\hline Mode & Frequency \\
\hline 1 & $21.454 \mathrm{~Hz}$ \\
\hline 2 & $21.751 \mathrm{~Hz}$ \\
\hline 3 & $22.794 \mathrm{~Hz}$ \\
\hline 4 & $38.868 \mathrm{~Hz}$ \\
\hline 5 & $40.431 \mathrm{~Hz}$ \\
\hline 6 & $41.489 \mathrm{~Hz}$ \\
\hline 7 & $57.114 \mathrm{~Hz}$ \\
\hline 8 & $62.036 \mathrm{~Hz}$ \\
\hline
\end{tabular}

Global methods analyze multiple sets of FRF data to estimate the frequencies, modal constants (residues), and modal damping. Ibrahim Time Domain (ITD), Eigensystem Realization Algorithm (ERA), Polyreference Frequency Domain (PFD) and Rational Fraction Polynomial (RFP) are some of the global modal analysis methods.

The Rational Fraction Polynomial method developed by Richardson and Formenti, 1985 [12] is described in the following section.

FRF can be expressed as a ratio of two polynomials as shown in

$$
H(\omega)=\frac{b_{0}+b_{1}(i \omega)+b_{2}(i \omega)^{2}+\ldots .+b_{2 N-1}(i \omega)^{2 N-1}}{a_{0}+a_{1}(i \omega)+a_{2}(i \omega)^{2}+\ldots .+a_{2 N}(i \omega)^{2 N}}
$$


In the RFP method, the unknown coefficients in the numerator and denominator are found using the curve fitting process. The modal parameters are related to numerator and denominator coefficients and modal parameters are obtained from the estimated numerator and denominator coefficients.

Error between measured FRF and theoretical value obtained from curve fitting FRF, can be defines as follows

$$
e_{k}=\frac{\left(b_{0}+b_{1}\left(i \omega_{k}\right)+b_{2}\left(i \omega_{k}\right)^{2}+\ldots .+b_{2 m-1}\left(i \omega_{k}\right)^{2 m-1}\right)}{\left(a_{0}+a_{1}\left(i \omega_{k}\right)+a_{2}\left(i \omega_{k}\right)^{2}+\ldots .+a_{2 m}\left(i \omega_{k}\right)^{2 m}\right)}-\tilde{H}_{k}
$$

where $\widetilde{H}_{k}=\tilde{H}\left(\omega_{k}\right)$, is the measured FRF data point and $\mathrm{m}$ is number of measured modes.

Equation 5.2 can be written in convenient form $e_{k}^{\prime}=\left(b_{0}+b_{1}\left(i \omega_{k}\right)+b_{2}\left(i \omega_{k}\right)^{2}+\ldots .+b_{2 N-1}\left(i \omega_{k}\right)^{2 m-1}\right)-\widetilde{H}_{k}\left(a_{0}+a_{1}\left(i \omega_{k}\right)+a_{2}\left(i \omega_{k}\right)^{2}+\ldots .+a_{2 N}\left(i \omega_{k}\right)^{2 m}\right)$ 
Rearranging, we get

$$
\begin{aligned}
& e_{k}^{\prime}=\left\{\begin{array}{llll}
1 & \left(i \omega_{k}\right) & \left(i \omega_{k}\right)^{2} \ldots . . & \left(i \omega_{k}\right)^{2 m-1}
\end{array}\right\}\left\{\begin{array}{c} 
\\
b_{0} \\
b_{1} \\
\ldots \\
b_{2 m-1}
\end{array}\right\}-\tilde{H}_{k}\left\{\begin{array}{llll}
1 & \left(i \omega_{k}\right) & \left(i \omega_{k}\right)^{2} \ldots . & \left(i \omega_{k}\right)^{2 m-1}
\end{array}\right\}\left\{\begin{array}{c} 
\\
a_{0} \\
a_{1} \\
\ldots \\
a_{2 m-1}
\end{array}\right\} \\
& -\tilde{H}_{k}\left(i \omega_{k}\right)^{2 m} a^{2 m}
\end{aligned}
$$

L linear equations similar to Equation 4.3 can be written for each of the $\mathrm{L}$ individual frequency points in the FRF. Combining the $\mathrm{L}$ such equations and writing it in matrix form, we obtain

$$
\{E\}_{L x 1}=[P]_{L x 2 m}\{b\}_{2 m x 1}-[T]_{L x 2 m}\{a\}_{2 m x 1}-\{W\}_{L x 1}
$$

The error criteria is defined as

$$
J=\left\{E^{*}\right\}^{t}\{E\}
$$

where ${ }^{*}$ denotes complex conjugate and ${ }^{t}$ denotes transpose

Solution to unknown coefficients can be achieved by minimizing the error function $J$ i.e., $\frac{\partial J}{\partial b}=0, \frac{\partial J}{\partial a}=0$. This leads to expression of the form

$$
\left[\begin{array}{cc}
{[Y]} & {[X]^{T}} \\
{[X]^{T}} & {[Z]}
\end{array}\right]\left\{\begin{array}{l}
\{b\} \\
\{a\}
\end{array}\right\}=\left\{\begin{array}{l}
G \\
F
\end{array}\right\}
$$


where

$$
\begin{aligned}
& {[Y]=\operatorname{Re}\left(\left[P^{*}\right]^{T}[P]\right) ;[X]=\operatorname{Re}\left(\left[P^{*}\right]^{T}[T]\right) ;[Z]=\operatorname{Re}\left(\left[T^{*}\right]^{T}[T]\right) ;[G]=\operatorname{Re}\left(\left[P^{*}\right]^{T}[W]\right) ;} \\
& {[F]=\operatorname{Re}\left([T *]^{T}[W]\right)}
\end{aligned}
$$

Equation 4.7 can be solved to determine $\{b\}$ and $\{a\}$, however it was found that $[P]$ and $[T]$ are ill-conditioned. The above equations can be reformulated using orthogonal polynomials for better conditioning. Further details can be found in reference [12]. The modal parameters can be derived from the numerator and denominator coefficients.

The RFP method mentioned above is only applicable for a single FRF and can be extended to multiple FRF data obtained using SIMO or MIMO tests. The RFP method can be applied to multiple FRFs by dividing the processing into two distinct steps: 1) estimate global frequencies and damping from all FRFs, one of the ways to do this is average together magnitudes of all FRFs and use the resulting FRF to obtain the frequencies and damping, and 2) process one FRF at a time to estimate the modal residue (thereby the mode shapes) using the global frequency and damping values estimated in step 1 [13].

Several modal analysis packages such as ICATS -MODENT, MEScope implement the Rational Fraction Polynomial (RFP) method. RFP method 
implemented in MODENT was used to extract the modal parameters of the FRP deck from the measured FRFs. The step-by-step procedure for obtaining modal parameters from MODENT using RFP method is presented below.

STEP 1: All the measured FRFs are imported into the modal analysis package in UFF 58 format (using LabVIEW Program written for this purpose, see Appendix A).

STEP 2: The frequency range over which the analysis has to be performed is chosen either by using a drag box on the FRF window or by selecting the frequency range.

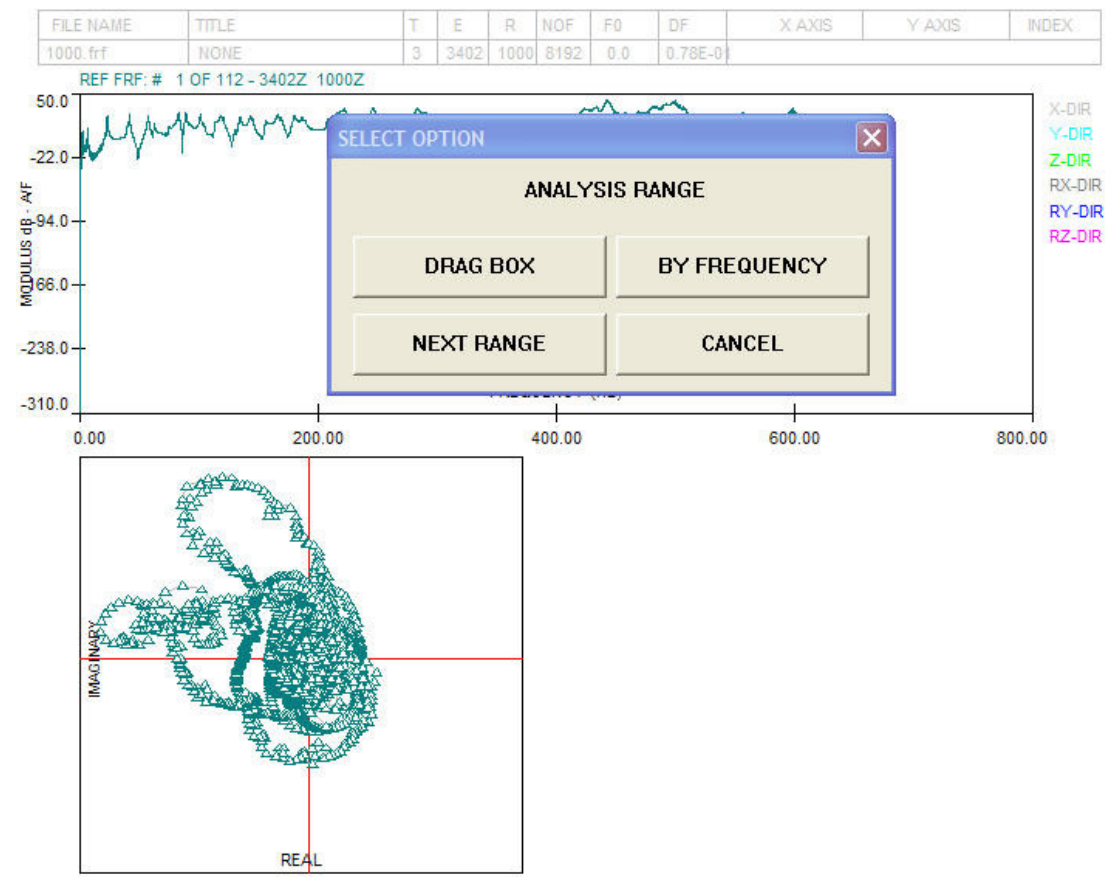

STEP 3: The MODENT software will select 16 randomly chosen points within the selected frequency range and analyze them for each run. 20 independent runs 
will be performed and the results are averaged. Confidence factors for each identified mode are also calculated by averaging the results from 20 runs. If a particular mode were to be found in 14 out of 20 runs, the confidence factor will be $70 \%$. In the analysis window shown below, two modes were found in $100 \%$ of the run, indicating consistency.

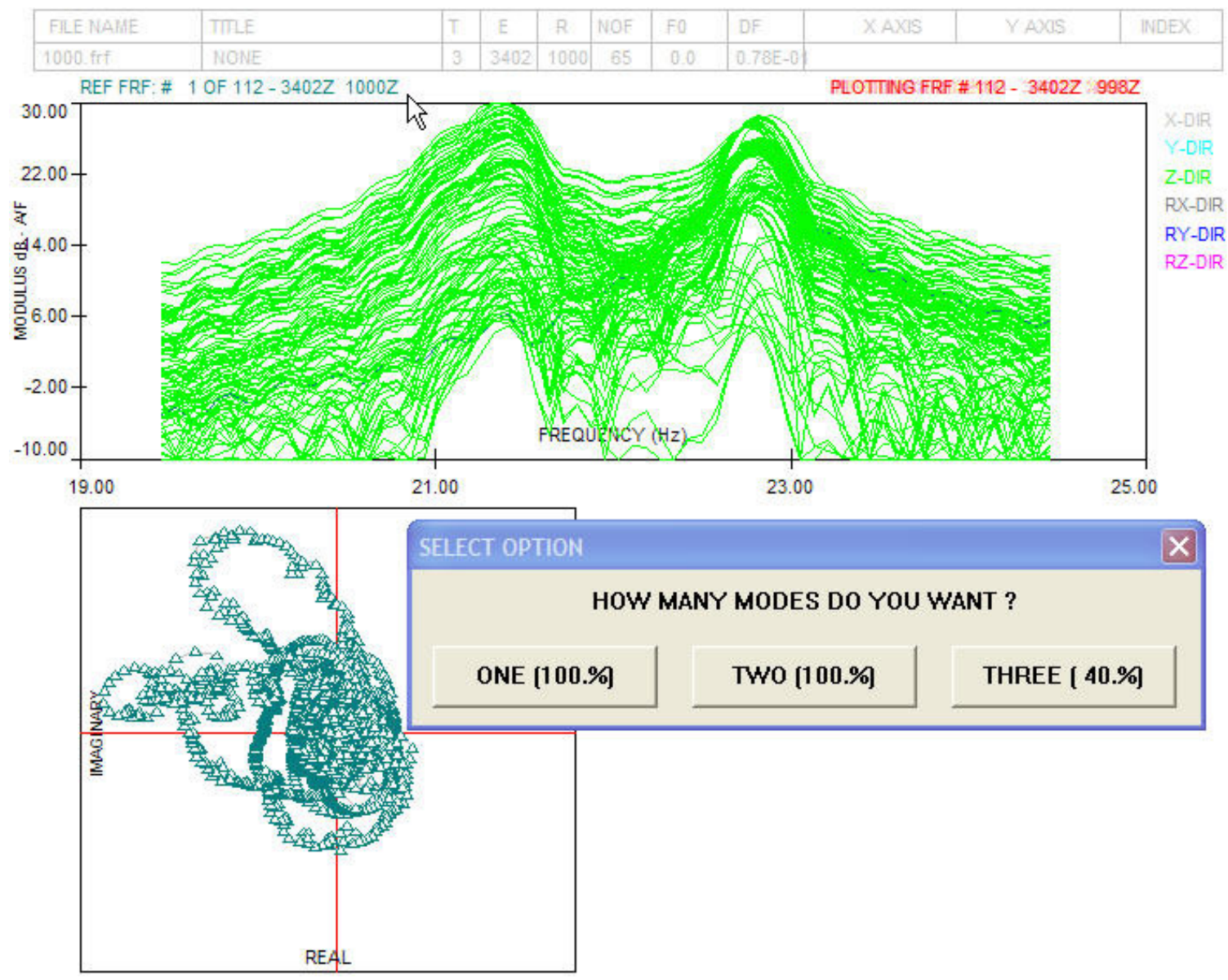

STEP 4: After the completion of 20 runs, the modal frequency and damping ratios will be displayed by selecting the two modes picked in all runs. At this 
stage, the user can select the frequency and other modal parameters for different modes and store them in a file.

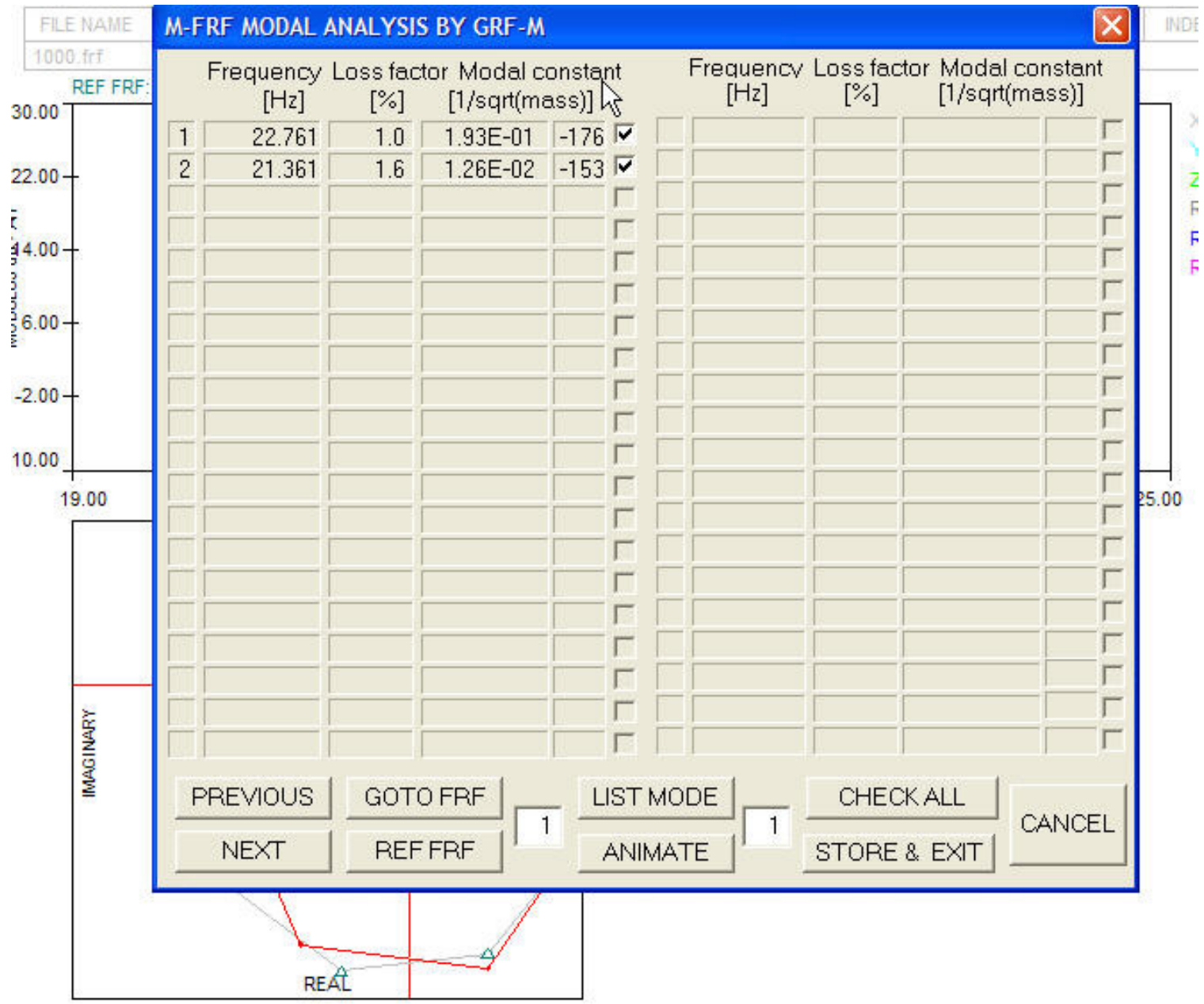

STEP 5: Steps 1 to 4 are repeated for analyzing all the desired frequencies in the FRFs. Proper care should be taken to identify closely spaced modes, data from a preliminary SDOF analysis on a few FRFs will be helpful in this regard. 


\section{CHAPTER 5 - CORRELATION OF FE AND EMA RESULTS}

\subsection{Introduction}

The most popular application of experimental modal analysis is to provide a comparison between predicted dynamic behavior (from a FE model), and actual dynamic behavior obtained from a modal test. First step is to have a direct comparison between the predicted and actual behavior of structure and to quantify the extent of difference between the two. Next, the sources of discrepancy in the FE model have to be identified and "adjusted" to reduce the discrepancy between the predicted and experimental dynamic properties (Ewins, 2000). The level of closeness required depends on the specific problem.

\subsection{Comparison of Natural Frequencies}

Initial comparison is made between the FE modal frequencies and experimental frequencies. A consistent error between the FE and experimental frequencies could indicate an error in material property or something as simple as using the wrong material density in the FE model. Table 5.1 provides a comparison of FE and experimental frequencies below $75 \mathrm{~Hz}$. 
Table 5.1 Experimental vs. FE Frequencies

\begin{tabular}{|c|c|}
\hline $\begin{array}{c}\text { FE Model } \\
\text { Frequencies }\end{array}$ & $\begin{array}{c}\text { Experimental } \\
\text { Frequencies }\end{array}$ \\
\hline $15.19 \mathrm{~Hz}$ & $21.37 \mathrm{~Hz}$ \\
\hline $17.54 \mathrm{~Hz}$ & $22.79 \mathrm{~Hz}$ \\
\hline $30.59 \mathrm{~Hz}$ & $38.13 \mathrm{~Hz}$ \\
\hline $30.79 \mathrm{~Hz}$ & $38.96 \mathrm{~Hz}$ \\
\hline $44.77 \mathrm{~Hz}$ & $40.49 \mathrm{~Hz}$ \\
\hline $46.09 \mathrm{~Hz}$ & $41.54 \mathrm{~Hz}$ \\
\hline $58.00 \mathrm{~Hz}$ & $57.16 \mathrm{~Hz}$ \\
\hline $61.60 \mathrm{~Hz}$ & $61.96 \mathrm{~Hz}$ \\
\hline $73.92 \mathrm{~Hz}$ & $71.34 \mathrm{~Hz}$ \\
\hline
\end{tabular}

As can be seen from Table 5.1, there is significant discrepancy between the FE and Experimental results. However, for a meaningful comparison between the two, the modes must be correlated and compared. Correlation between modes can be done visually or using a parameter known as 'Modal Assurance Criterion' or MAC.

Modal Assurance Criterion (MAC) is defined as follows:

$$
M A C=\frac{\left|\left\{\psi_{X}\right\}^{T}\left\{\psi_{A}\right\}\right|^{2}}{\left(\left\{\psi_{X}\right\}^{T}\left\{\psi_{X}\right\}\right)\left(\left\{\psi_{A}\right\}^{T}\left\{\psi_{A}\right\}\right)}
$$

where $\left\{\psi_{A}\right\}=$ theoretically predicted mode shape.

$$
\left\{\psi_{X}\right\}=\text { experimentally measured mode shape. }
$$

A MAC value of 1 or $100 \%$ indicates perfect correlation between the two mode compared, a value of 0 indicates no correlation. MODESH, a module in the 
MODENT software suite has a provision for comparison frequencies and computation of MAC values, among other things. Figure 5.1 shows the frequency plot and MAC chart for the experimental and FE results.

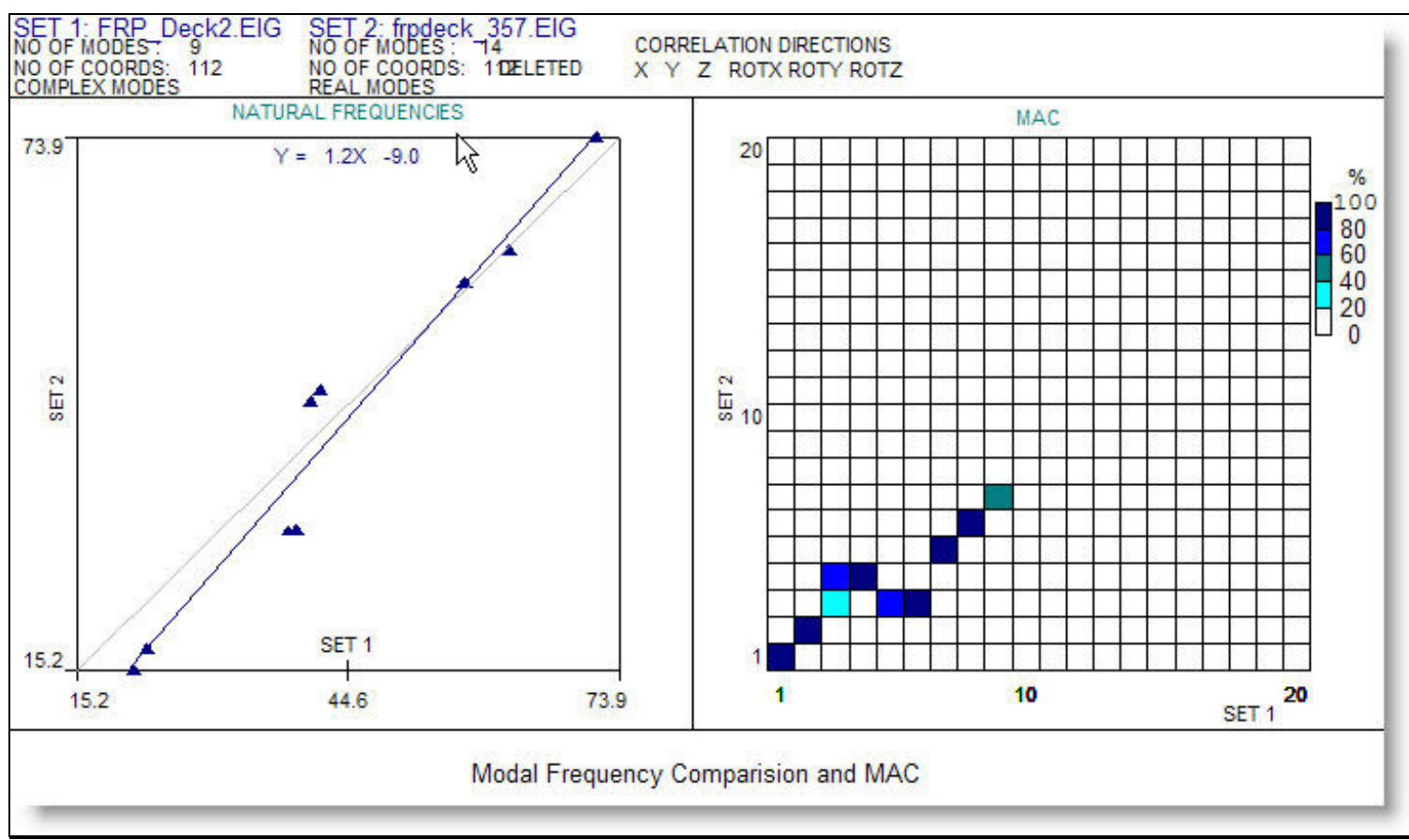

Figure 5.1 Modal Frequency Comparison and MAC

Another useful format for comparison of frequencies is plotting the experimental and FE frequencies on $X$ and $Y$ axes (Figure 5.1). Also, seen in Figure 5.1 is chart with MAC computations between different modes of FE and experiment. A dark blue (or dark colored) box indicates the MAC value is close to $100 \%$, indicating the two modes are correlated and are known as 'correlated mode pairs'. Modes 1, $2 \& 4$ obtained using FE analysis and experiment are correlated whereas mode 3 of FE is correlated with mode 6 of experiment. Modes $5 \& 6$ of FE correlate well 
with modes $7 \& 8$ of experiment. Now, the frequency comparison will be useful in determining any errors in FE modeling.

Table 5.2 Frequency Comparison between Correlated Mode Pairs

\begin{tabular}{|c|c|c|}
\hline FE Model Freq (Hz) & Exp Freq $\mathbf{( H z )}$ & \% Diff \\
\hline 15.19 & 21.37 & 40.68 \\
\hline 17.54 & 22.79 & 29.93 \\
\hline 30.79 & 38.96 & 26.53 \\
\hline 30.59 & 41.54 & 35.80 \\
\hline 44.77 & 57.16 & 27.67 \\
\hline 46.09 & 61.96 & 34.43 \\
\hline
\end{tabular}

\subsection{Comparison of Mode Shapes}

At this stage, it will be useful to look at the modeshapes obtained from FE analysis and through experiment to gain insight into the large discrepancy in the frequency values. Figure 5.2 shows the modeshapes of Mode 1 obtained from FE and experiment, as mentioned earlier, have a MAC value of close to $100 \%$ i.e., they are correlated mode pairs. Mode 1 in both FE and experiment are torsional modes, the lower frequency obtained through FE indicates that the torsional stiffnesses of deck used in FE (Figure 3.4) are lower than the actual torsional stiffnesses of the deck in addition to influence of boundary conditions and extra thickness at the joints of the deck. It should be noted that the material properties shown in Figure 3.4 are obtained from testing of individual deck modules, which behave more like beams and there is no plate action. One other parameter which has significant influence on frequencies is the density of material used in the FE 
model, use of higher density than actual will result in all the frequencies obtained from FE to be lower than experimentally obtained modal frequencies. However, the value shown in Figure 3.4 was double checked and is accurate.
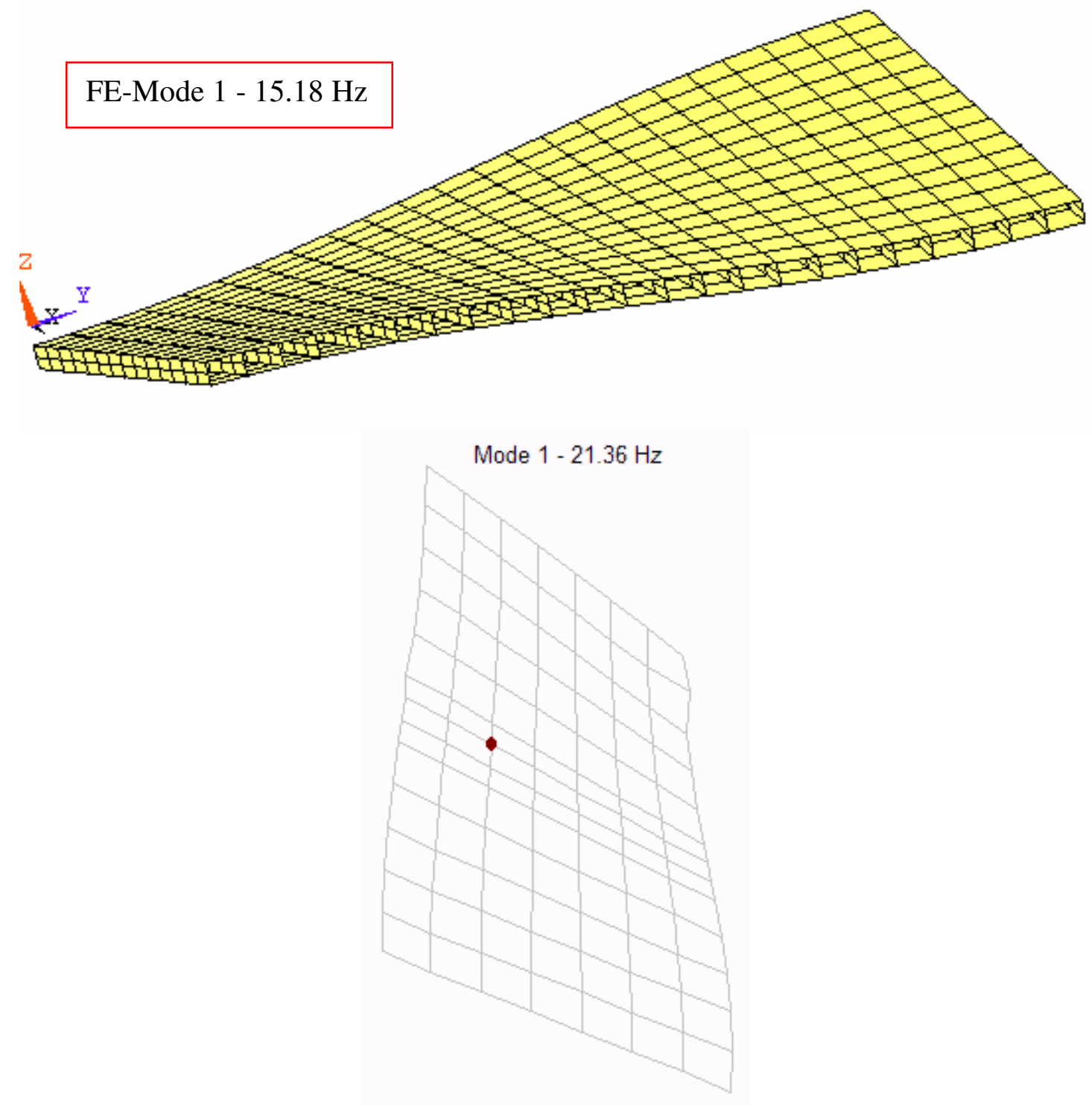

Figure 5.2 Comparison of FE vs. Exp Modeshapes -Mode 1 
Next, the second modes from FE and experiment are plotted in Figure 5.3, they are also a correlated mode pair. The second mode is the first bending mode in the $\mathrm{Y}$ direction of the deck. The $\mathrm{X}$ direction of the deck is the cell direction, $\mathrm{Y}$ direction of the deck is along the length of the deck and $\mathrm{Z}$ direction is along the depth of the deck.
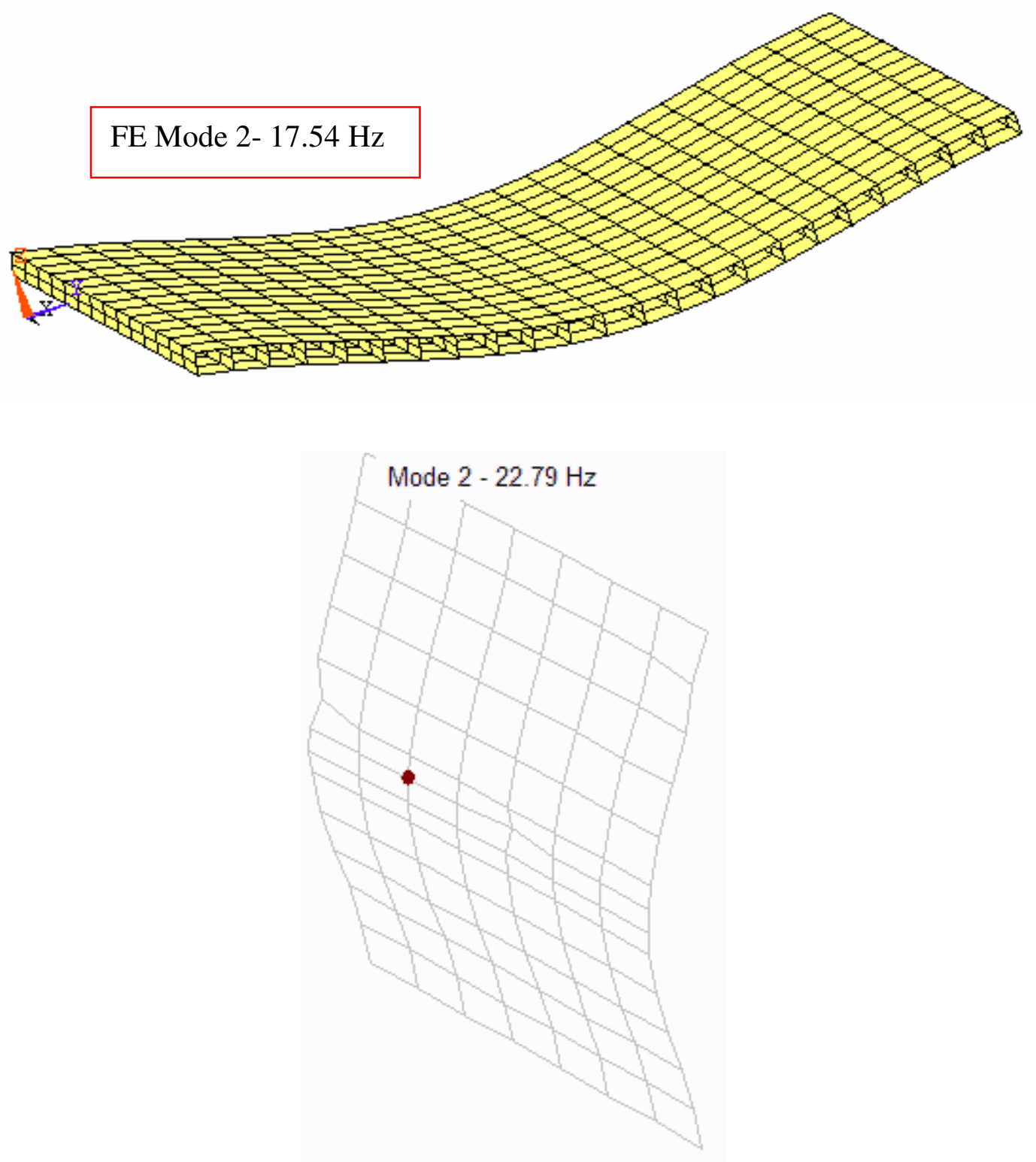

Figure 5.3 Comparison of FE vs. Exp Modeshapes -Mode 2 
Although, the first bending modeshapes are well correlated (MAC close to $100 \%$ ), the frequency obtained through the FE model is almost $30 \%$ lower than experimental value. This indicates that the stiffness value $\left(\mathrm{E}_{\mathrm{y}}\right)$ in $\mathrm{Y}$-direction used in FE model is lower than actual stiffness of deck. Here again, the deck property $E_{y}$ was measured on a single deck module which acts as a beam type structure. Similar comparison can be made for other correlated mode pairs (CMPs), the mode shapes for other CMPs are shown in Appendix B.

\subsection{Updating the FE model}

As discussed in the previous section, there is a mismatch in frequency between the CMPs while the MAC value is close to $100 \%$. Frequency mismatch for all modes of vibration could be due to three reasons: 1) the actual FRP deck is stiffer than the FE model, 2) boundary conditions could have some influence on some or all of vibration modes, and 3) increased thickness at joints due to reinforcement (not accounted for in original FE model). From the first torsion and bending mode frequencies mismatch, it is obvious that $\mathrm{G}_{\mathrm{xy}}$ and $\mathrm{E}_{\mathrm{y}}$ used in $\mathrm{FE}$ is lower than actual FRP deck Ey. Comparisons of frequencies of other CMPs between FE and experimental as shown in Appendix B reinforce the conclusion that the $E_{y}$ and $G_{x y}, G_{y z}$ and $G_{x z}$ used in FE model are lower than the actual FRP deck. 
Coupon level tests on Prodeck 4 module to determine the $\mathrm{E}_{\mathrm{y}}$ revealed a value of $2.5 \times 10^{6}$ psi [Personal communication with Vimala Shekar, 2005]. This is much higher than the $\mathrm{E}_{\mathrm{y}}$ value at component level (beam tests) of $1.4 \times 10^{6} \mathrm{psi}$ reported by [4]. The lap joints for Prodeck 4 do not efficiently transfer the forces between the two modules, especially in a beam type structure, which explains the significant loss of stiffness due to presence of the joints. However, in this case where the structure acts more like a plate, a higher value of $\mathrm{E}_{\mathrm{y}}$ than 1.4 million psi could be expected even in the presence of same lap joints due to plate-action. Also, the joints are reinforced using glass fabrics thereby having higher thickness.

The FE model was updated based on the above comparisons of the FE and experimental results. The FRP deck model was modified based on the three sources of error in modeling mentioned above. The three updating parameters were: 1) modified materials properties, 2) including the suspension mechanism in the FE model, and 3) updating the thickness at the joints. Figure 5.4 lists the modified material properties used for the FRP deck, and the same density of FRP deck was used. Higher $G_{x y}, G_{y z}$ and $G_{x z}$ were also used to better simulate the behavior of FRP deck. A nominal transverse stiffness value of 1 million psi was used to model the lap joints of the FRP deck. Figure 5.5 lists the material properties used for modeling the lap joint. 


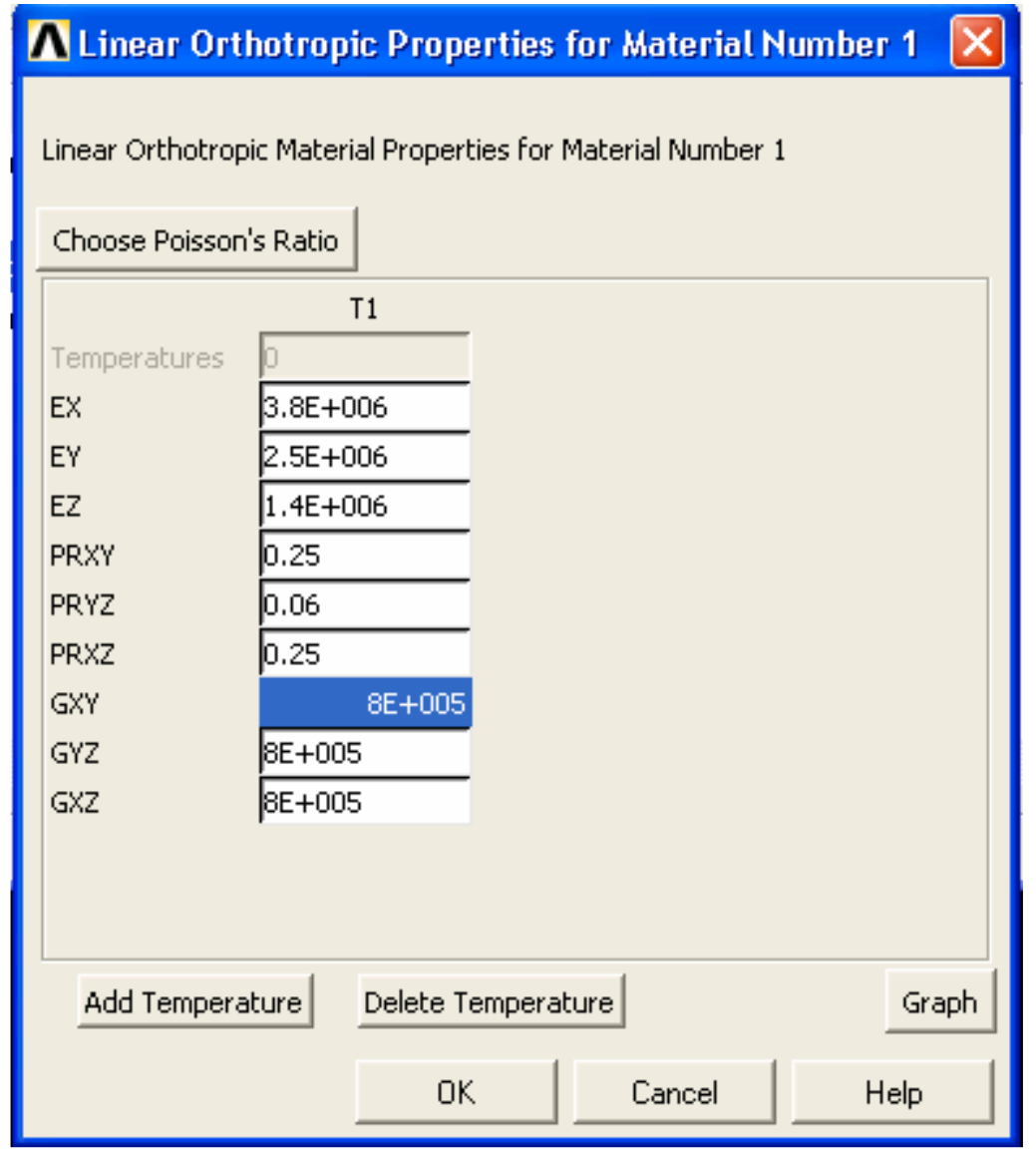

Figure 5.4 Modified FRP deck properties used in FE model 


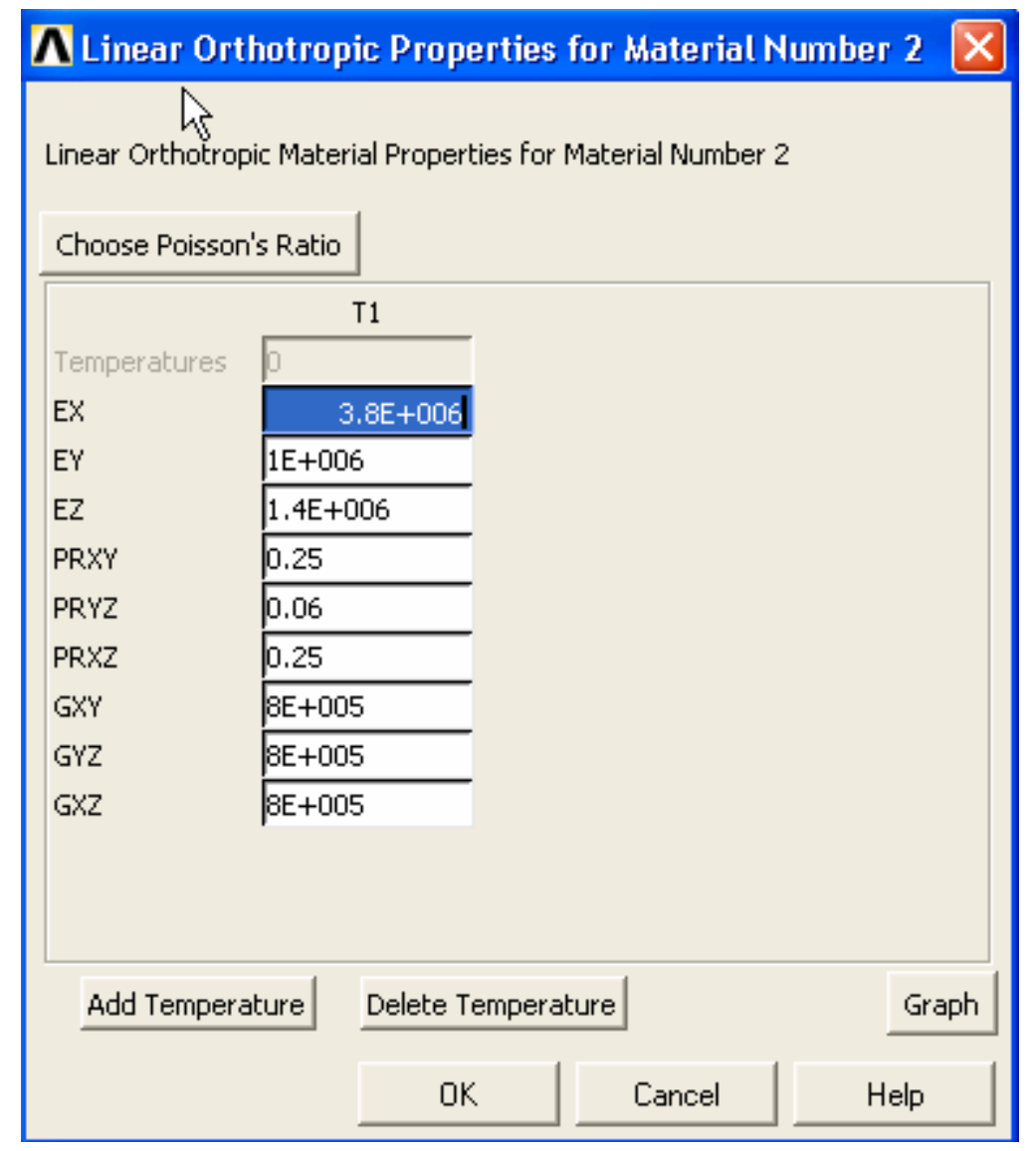

Figure 5.5 Material properties used to model the lap joints

The mesh for the modified FE model is shown in Figure 5.6, the different colors in the mesh represent the different material properties and thicknesses used. The size of mesh remained unchanged from the original FE model. The spring stiffness for the nylon suspension was estimated so as to match the highest rigid body mode of the FE model with the experimental equivalent. A stiffness of 6700 $\mathrm{lb} /$ in was used. The joint element thickness was updated from a value of $0.43^{\prime \prime}$ to 0.875 " based on actual measurements on the FRP deck. 


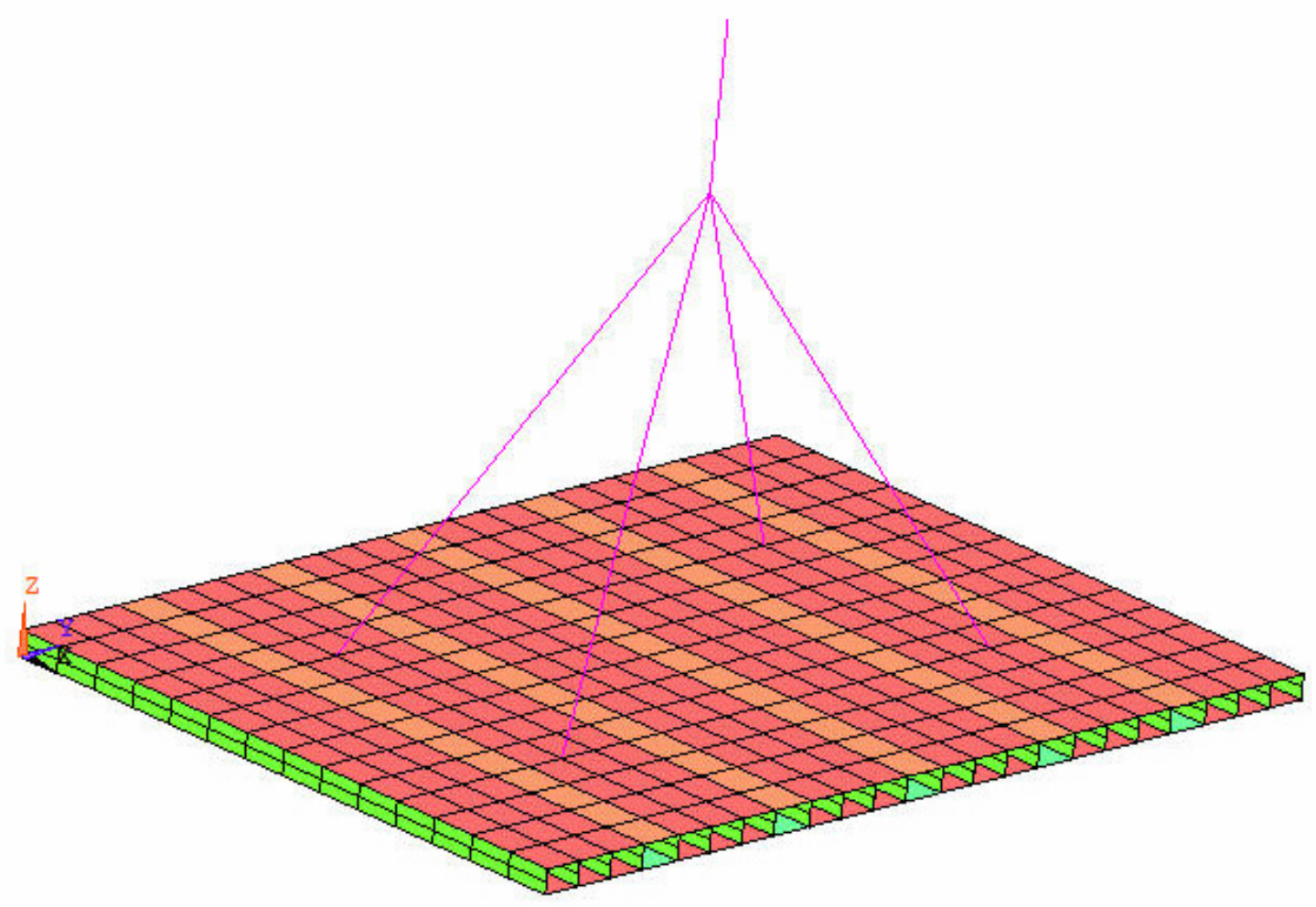

Figure 5.6 Mesh of modified FE model for FRP Deck

\subsection{Frequency Comparison- Updated FE vs. Experimental Results}

Updating the FE model by modifying the material properties did not change the pattern of modes, i.e., the first mode is still the torsional mode and second mode is the first bending mode along the Y-direction and so on. But, the correlated mode pair frequencies of the updated model were higher than the original model. The correlated mode pairs between the updated FE model and experimental results were identified based on visual inspections, MAC values 
were not recalculated (Figure 5.7). The frequency comparison of CMPs of updated FE model and experimental results is shown in Table 5.4

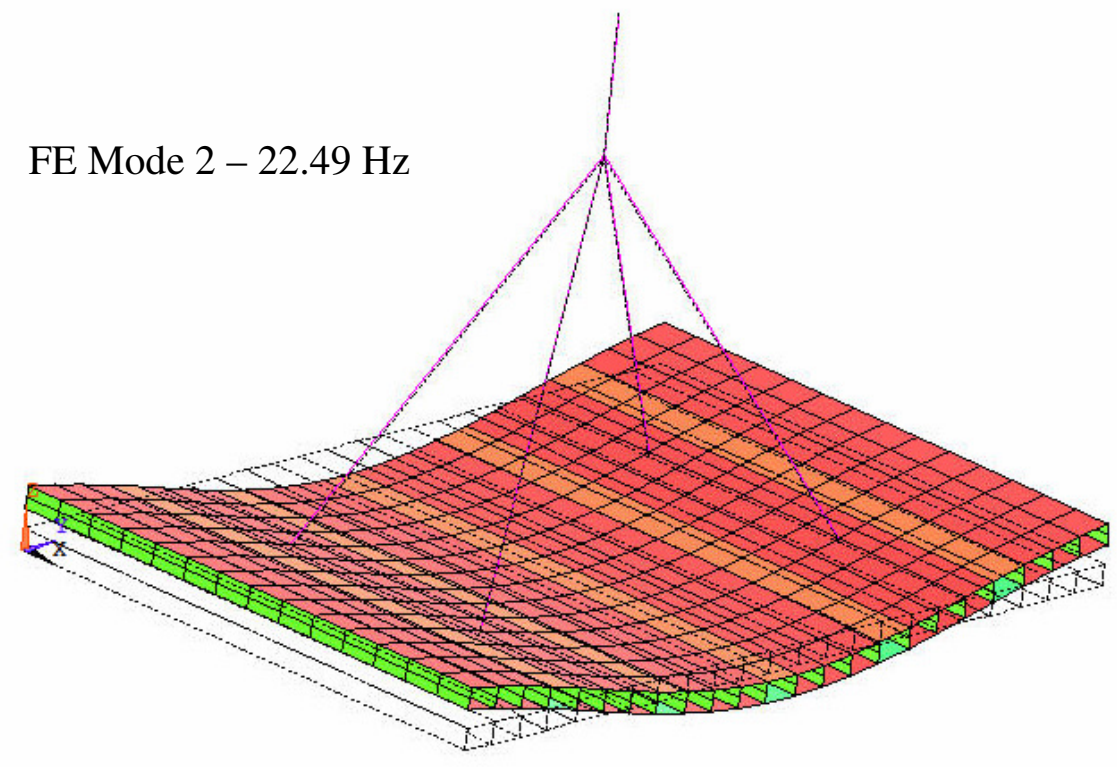

a)

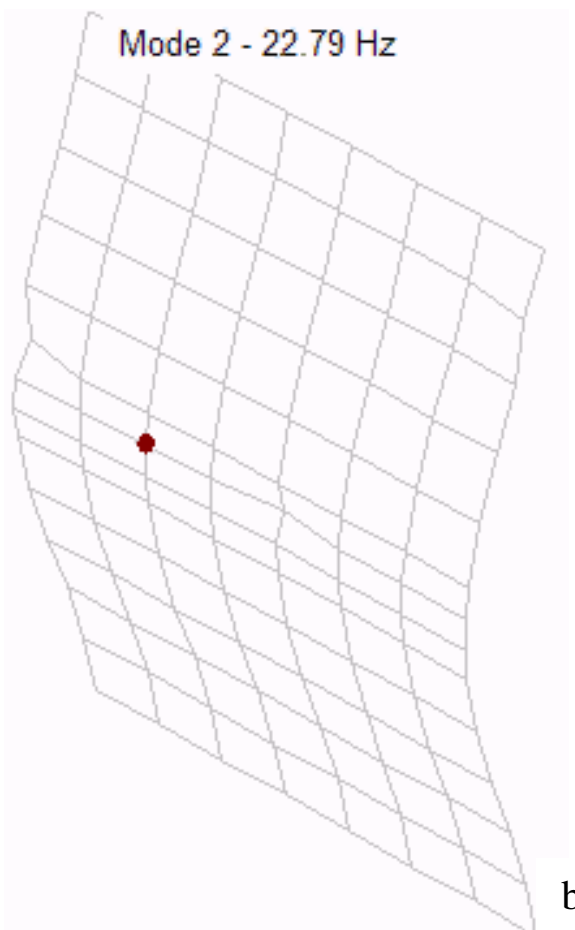

Figure 5.7 Second Mode, a) Updated FE - 22.49 Hz, b) $\operatorname{Exp}-22.79 \mathrm{~Hz}$ 
Table 5.3 Frequency Comparison between Correlated Mode Pairs of Updated FE Model and Experiment

\begin{tabular}{|c|c|c|}
\hline Updated FE Model Freq (Hz) & Exp Freq (Hz) & \% Diff \\
\hline 22.17 & 21.37 & 3.60 \\
\hline 22.49 & 22.79 & 1.33 \\
\hline 40.56 & 38.96 & 1.47 \\
\hline 39.93 & 41.54 & 1.71 \\
\hline 60.09 & 57.16 & 4.87 \\
\hline 60.55 & 61.96 & 2.32 \\
\hline
\end{tabular}

As seen in Table 5.4, the difference between experimental and FE frequencies has dropped from $26.53 \%-40.68 \%$ range to $1.33 \%-4.87 \%$ range, indicating that the updated FE model better simulates the dynamic behavior of the FRP deck.

These updated models of the FRP deck can be used in simulate the response of the FRP deck trailer due to various dynamic loads. In another application, the updated FE model of FRP deck can be used as part of any multi-body dynamics model of the FRP trailers using ADAMS. Usually, the multi-body dynamics models use rigid parts for modeling, FE data can be used to incorporate flexibility into any part of the model improving its simulation results.

By updating the shear stiffness values $\left(\mathrm{G}_{x y}, \mathrm{G}_{y z}\right.$ and $\left.\mathrm{G}_{\mathrm{xz}}\right)$, the error in frequencies between the FE model and experimental is reduced, however, there is no theoretical or experimental basis for these values. The stiffness values were 
updated by observing the physical behavior of the dynamics of FRP deck obtained experimentally. It is recommended that shear properties should be validated through full scale testing of FRP deck. 


\section{CHAPTER 6 - SUMMARY AND CONCLUSIONS}

\subsection{Summary}

Prodeck 4, a lightweight low profile FRP deck developed primarily as a bridge deck, is being evaluated as part of a new generation FRP trailer design for the Medium Tactical Vehicle Replacement (MTVR). Part of evaluation of the new FRP trailer design included building a detailed FE model and predicting the response of the trailer under different operational and transportational loads. The Prodeck 4 module is a new system and has orthotropic material properties, therefore an FE model of FRP deck that is validated through experimental data will ensure confidence in results obtained from the FE model for the full trailer. The objectives of this research were to: 1) obtain frequencies and mode shapes using FE model, 2) conduct experimental modal testing on the FRP deck to obtain the frequencies and mode shapes, and 3) update the FE model based on modal test data.

A FE model was built for the FRP deck in ANSYS ${ }^{\circledR}$ using Shell93 elements. Material properties used in the FE model were based on previous static testing of FRP deck. Frequencies and mode shapes were obtained from the FE model. Results from the FE analysis were used for test planning of the FRP deck, the best 
suspension points, the best accelerometer location, and the best impact locations were determined. A test setup for FRP deck was designed based on the test planning. Single input single output (SISO) test was conducted using an impact hammer and one accelerometer as reference, a SISO test was chosen due to time constraints.

Post processing was performed on the data acquired from the FRP deck by applying windows on input and response data and "zero-padding" the data to increase the frequency resolution before computing the FRFs. The data from four trials was averaged and converted to UFF58 format. Rational Fraction Polynomial (RFP) method was chosen as the modal parameter estimation algorithm. MODENT, a modal analysis package implements the RFP method and this method was used for extracting the modal parameters (frequencies, mode shapes and, damping).

Experimental and FE results were compared through comparison of correlated mode pair frequencies, visual inspection of mode shapes and calculation of MAC values. Results indicated that while MAC values for correlated mode pairs were in perfect agreement the frequencies between $\mathrm{FE}$ and experiment were significantly different (26.53\%-40.68\% error). Visual inspection of mode shapes of both FE and experiment revealed that the Y-direction of FRP deck and the torsional stiffness values used in FE might be lower than actual. The stiffness 
values, thickness at joints, were updated based on these observations and the FE analysis was repeated by including realistic boundary conditions.

\subsection{Conclusions}

The error between FE and experimental values of frequency has reduced to $1.33 \%-4.87 \%$ range after updating, from an original error of $26.53 \%-40.68 \%$. Correlated mode pairs have shown a MAC value of close to $100 \%$, revealing perfectly correlated mode shapes. However, there is no one-to-one correspondence between the modes in FE and experiment, i.e., modes 1, 2 \& 4 obtained using FE and experiment are correlated whereas mode 3 of FE is correlated with mode 6 of experiment. Modes $5 \& 6$ of FE correlate well with modes $7 \& 8$ of experiment. Also, there are a couple of modes obtained experimentally that were not predicted by the FE model. Therefore, it can be stated that updated FE model is not "completely correct."

Even though the updated FE model is not perfectly correlated with experiment, it will serve a few purposes such as using the updated FE results to create a flexible part for the FRP deck in the multi-body dynamics model of the FRP trailer. In addition, the updated model can be used in predicting the dynamic response which is dominated by the fundamental and maybe second mode of vibration. 
To reduce the computation time a coarse mesh was used, therefore this model cannot be used to predict the local vibration response of the FRP deck.

Certain applications would require further refinement of the FE Model. Further refinement of the FE model can be achieved through several ways: 1) introducing some compliance in the lap joint of contiguous FRP modules to better simulate the inadequate force transfer between modules, 2) consider modeling the deck using layer-by-layer properties, 3) accurately modeling the shape of the deck, including the slopes on overhanging flanges, and 4) refine the mesh for local flange and web vibration prediction.

The shear stiffness values $\left(G_{x y}, G_{y z}\right.$ and $\left.G_{x z}\right)$ used in FE model has to be validated through full scale testing of FRP deck. 


\section{REFERENCES}

[1] D Punyamurthula

Structural Performance of Low-profile FRP Composite Cellular Modules Master's Thesis, West Virginia University, Morgantown. 2005.

[2] W Prachasaree

Shear Behavior and Performance of FRP Composite Bridge Deck

PhD Dissertation, West Virginia University, Morgantown. 2005

[3] P Munugalla

Fatigue Life Prediction of GFRP Composite Material at Coupon and Component Level.

Master's Thesis, West Virginia University, Morgantown. 2005

[4] H GangaRao, V Shekar, D Punyamurthula, W Prachasaree

Structural Performance of Prodeck 4

CFC-WVU Report No. 05-001. 2005

[5] Ansys Release 8.1 Documentation

ANSYS, Inc.

[6] E J Barbero

Introduction to Composite Materials Design.

Taylor \& Francis. Philadelphia, PA. 1998

[7] D J Ewins

Modal Testing: Theory, Practice and Application; 2nd edition.

Research Studies Press. Hertfordshire, UK. 2001

[8] N Imamovic

Validation of Large Structural Dynamics Models Using Modal Test Data. PhD Thesis, Imperial College. London. 1998.

[9] D C Kammer

Sensor Placement for On-Orbit Modal Identification and Correlation of Large Space Structures.

Journal of Guidance, Control, and Dynamics. Vol 14. No.2. 251-259. 1991

[10] LabVIEW Function and VI Reference Manual

National Instruments. 1998. 
[11] R J Allemang

Vibrations: Analytical and Experimental Modal Analysis

UC-SDRL-CN-20-263-662, University of Cincinnati. 1999

[12] M H Richardson and D L Formenti

Parameter Estimation from Frequency Response Measurements using Rational Fraction Polynomials

$1^{\text {st }}$ IMAC Conference, Orlando, FL. 1982

[13] M H Richardson and D L Formenti

Global Curve Fitting of Frequency Response Measurements using the Rational Fraction Polynomial Method

$3^{\text {rd }}$ IMAC Conference, Orlando, FL. 1985. 


\section{APPENDIX A - LabVIEW Program Descriptions}

Three LabVIEW programs were written for, 1) signal processing of the time domain data and calculation of frequency response functions (FRFAutomatic.vi), 2) averaging the frequency response functions obtained from different sets of data from each node (FRF_Average.vi), and 3) a program to convert the averaged FRF data file into UFF58 format FRF file. All three programs are described in detail in this appendix.

\section{FRF-Automatic.vi}

This VI reads "raw" time domain data files which were generated from Siglab data acquisition system and performs the required signal processing on the data and calculates the Frequency Response Functions for each test trial. The input for this VI is a text file containing the list of nodes of the structure. The raw time domain data should be stored in "Node\#-Trial\#.txt" e.g., 1000-2.txt. The VI reads automatically reads four trials (sets) of the time domain data files for each of the nodes listed in input file, and outputs a "Node\#-Trial\#.frf" file.

\section{Controls and Indicators}

Dampling Rate

$\mathrm{dt}$ is the sample period of the time-domain signal, usually in seconds. It is also $1 /$ fs where fs is the sampling frequency of the time-domain signal.

[문] Impact Hammer

Fi国 FRF-Magnitude

區司 FRF-Phase

[DikL] Accelerometer

56LL Output Array 


\section{Front Panel}

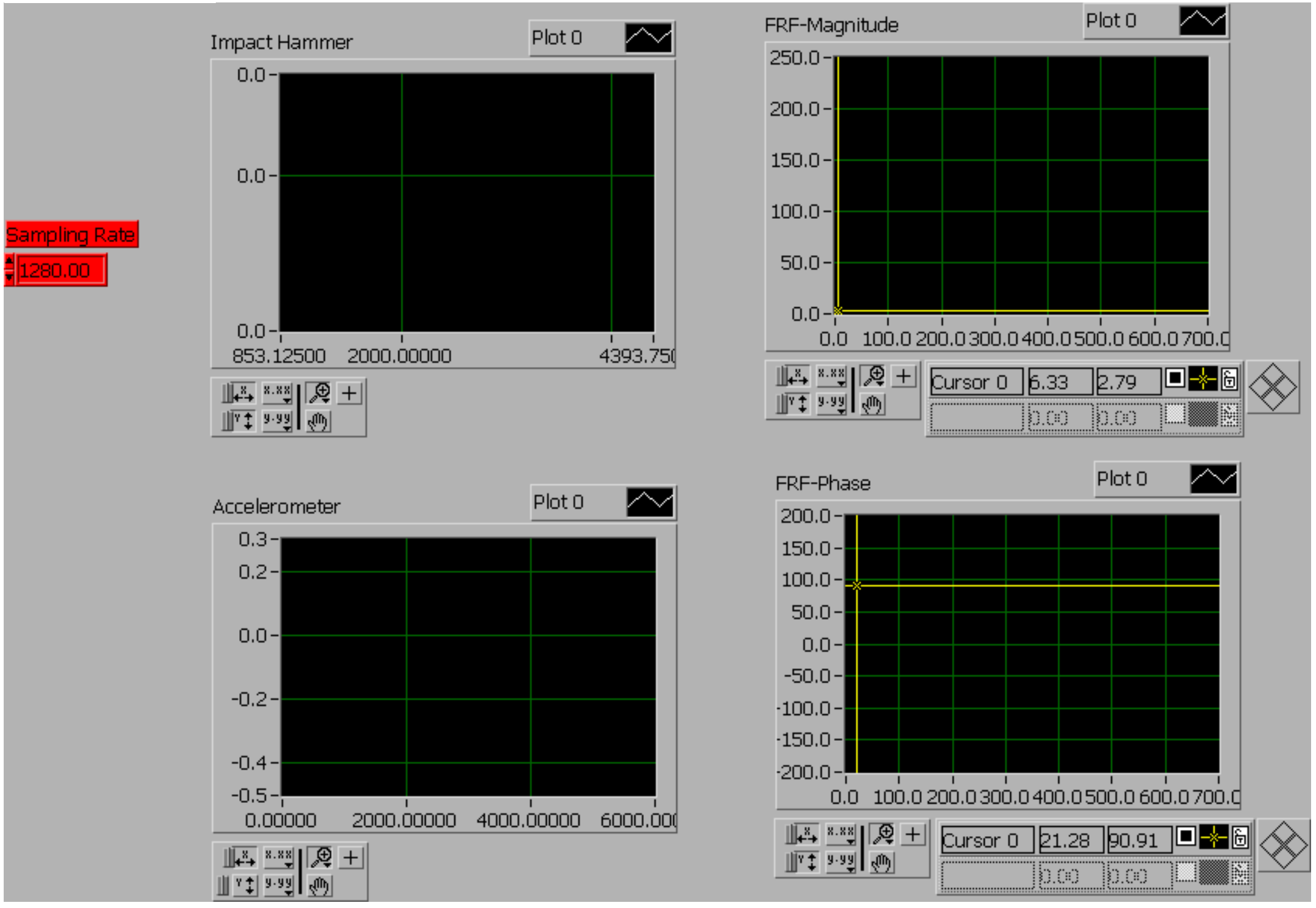




\section{Block Diagram}

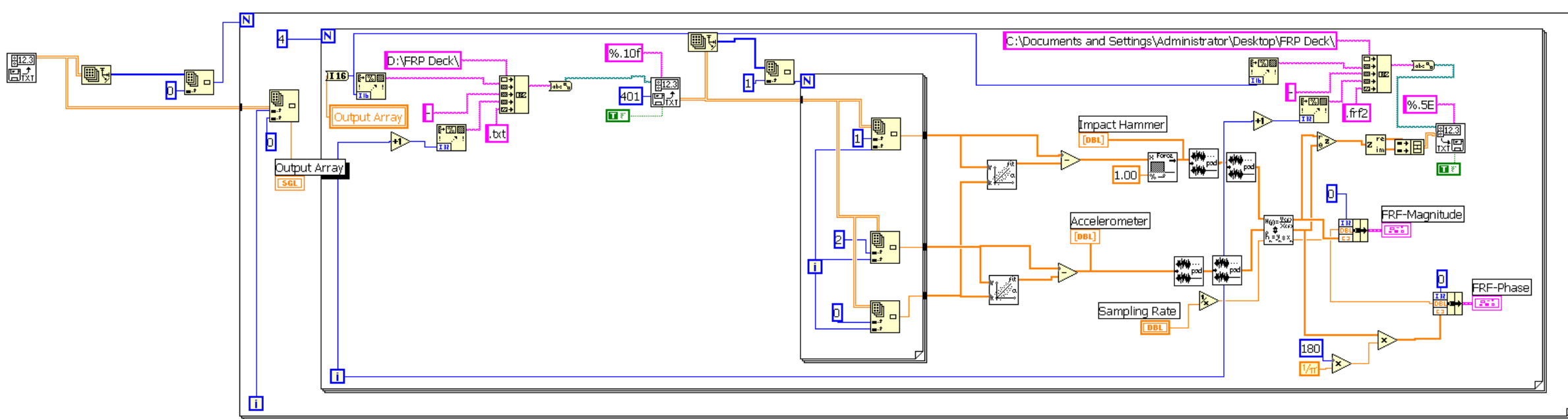




\section{List of SubVIs}

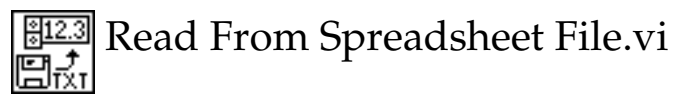

$\mathrm{C}: \backslash$ Program Files $\backslash$ National

Instruments $\backslash$ LabVIEW $\backslash$ vi.lib $\backslash U$ tility $\backslash$ file.llb $\backslash$ Read From Spreadsheet

File.vi

Force Window.vi

C: $\backslash$ Program Files $\backslash$ National

Instruments $\backslash$ LabVIEW $\backslash$ vi.lib $\backslash$ Analysis $\backslash 4$ window.llb $\backslash$ Force Window.vi

Linear Fit.vi

C: \Program Files $\backslash$ National

Instruments $\backslash$ LabVIEW $\backslash$ vi.lib $\backslash$ Analysis $\backslash 6$ fits.llb $\backslash$ Linear Fit.vi

Transfer Function.vi

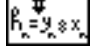

C: $\backslash$ Program Files $\backslash$ National

Instruments $\backslash$ LabVIEW $\backslash$ vi.lib $\backslash$ Analysis $\backslash 0$ measdsp.llb $\backslash$ Transfer Function.vi

Zero Padder.vi

C: $\backslash$ Program Files $\backslash$ National

Instruments $\backslash$ LabVIEW $\backslash$ vi.lib $\backslash$ Analysis $\backslash 2$ dsp.llb $\backslash$ Zero Padder.vi

Write To Spreadsheet File.vi

通回

C: $\backslash$ Program Files $\backslash$ National

Instruments $\backslash$ LabVIEW $\backslash$ vi.lib $\backslash U$ tility $\backslash$ file.llb $\backslash W$ rite To Spreadsheet File.vi 


\section{FRF_Average.vi}

This VI automatically reads the different sets of FRF data files and calculates the average and writes the output to a new file. The input for this VI is a text file containing the list of nodes on the structure.

\section{Front Panel}

Output Array

1000.0C

\section{Controls and Indicators}

5[GL Output Array 


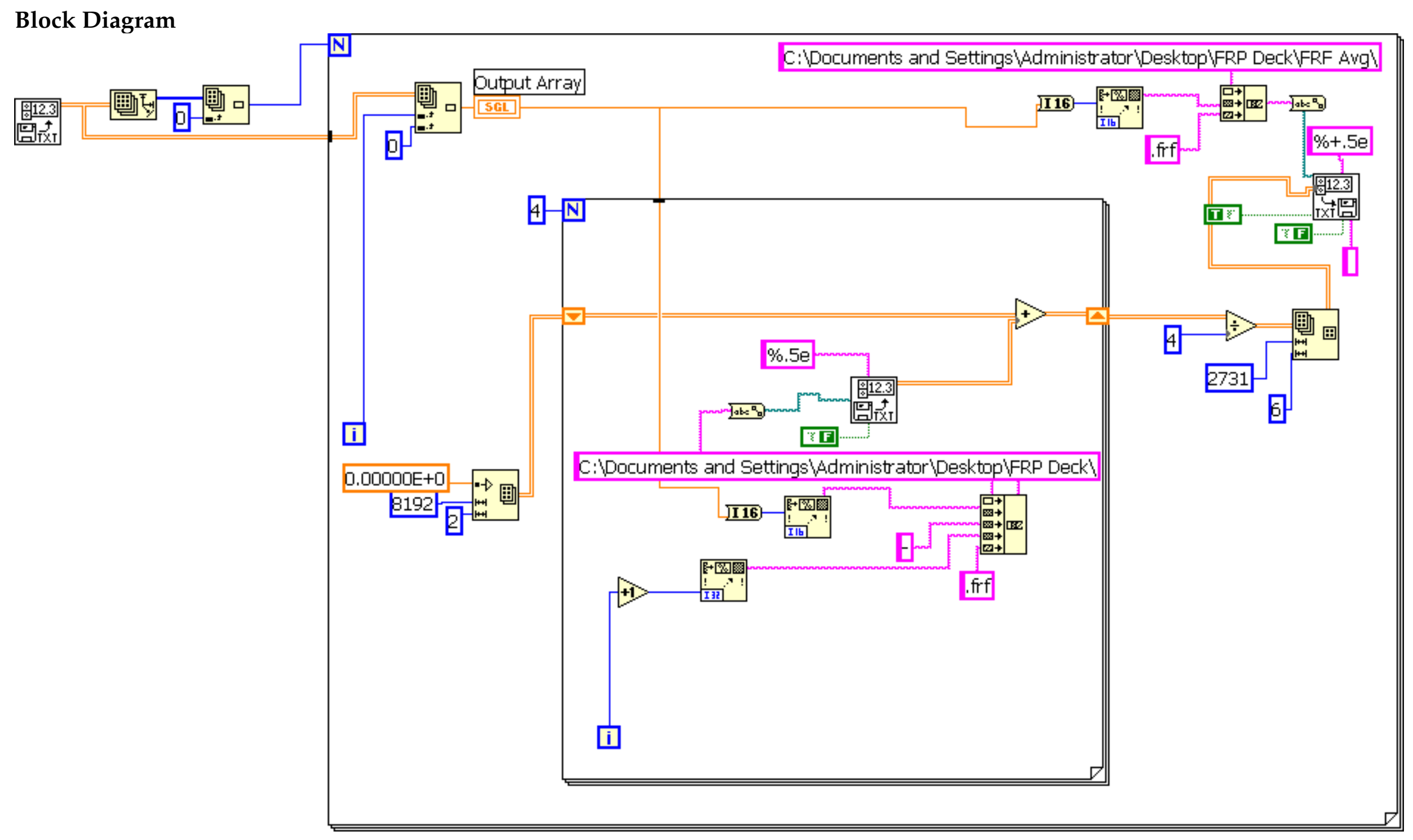




\section{List of SubVIs}

Read From Spreadsheet File.vi

回部

C: $\backslash$ Program Files $\backslash$ National

Instruments $\backslash$ LabVIEW $\backslash$ vi.lib $\backslash U$ tility $\backslash$ file.llb $\backslash$ Read From Spreadsheet

File.vi

Write To Spreadsheet File.vi

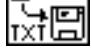

C: $\backslash$ Program Files $\backslash$ National

Instruments $\backslash$ LabVIEW $\backslash$ vi.lib $\backslash U$ tility $\backslash$ file.llb $\backslash W$ rite To Spreadsheet File.vi 


\section{UFF58.vi}

This VI automatically converts the FRF data file into UFF58 file format. The user has to input the following information: 1) Reference Node \#, 2) Response Direction, 3) Reference Direction, 4) \# of Pts in FRF, 5) Delta F (Frequency resolution of FRF). The input for this VI is a text file containing the list of nodes on the structure.

\section{Front Panel}

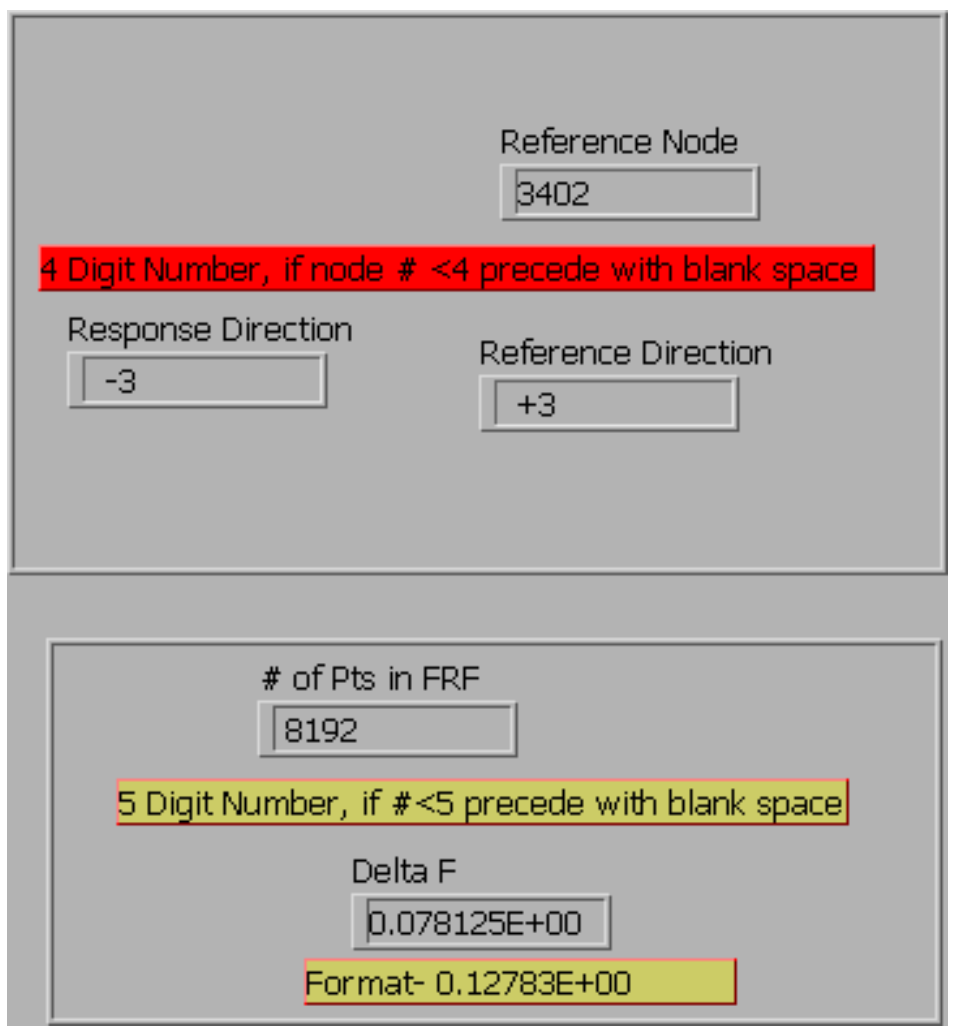

\section{Controls and Indicators}

Response Direction

Reference Node

Reference Direction 
\# of Pts in FRF

Delta F

\section{Block Diagram}

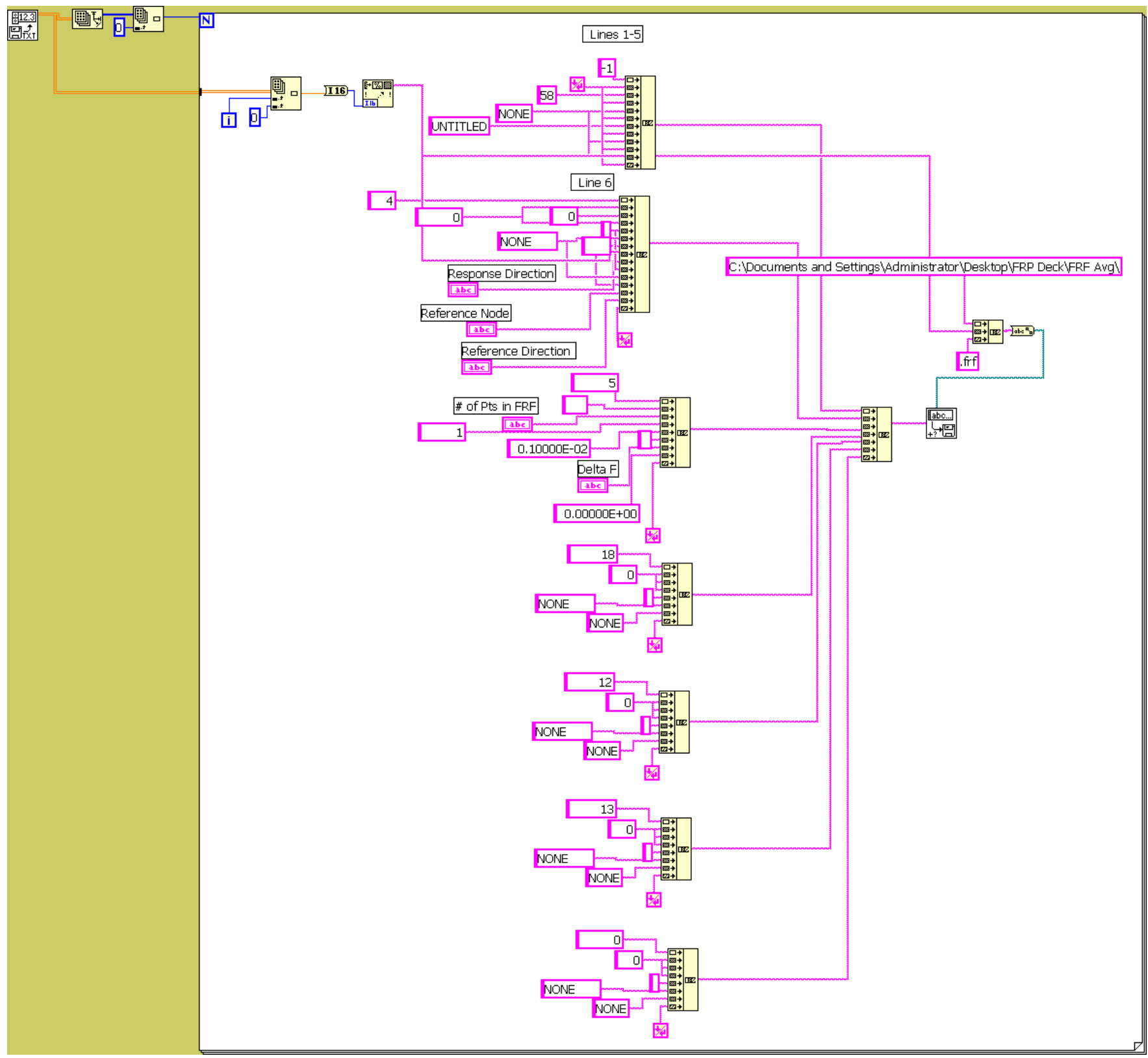




\section{List of SubVIs}

Write Characters To File.vi

$\rightarrow+\square$

C: $\backslash$ Program Files $\backslash$ National

Instruments $\backslash$ LabVIEW $\backslash$ vi.lib $\backslash U$ tility $\backslash$ file.llb $\backslash W$ rite Characters To File.vi

Read From Spreadsheet File.vi

$\mathrm{C}: \backslash$ Program Files $\backslash$ National

Instruments $\backslash$ LabVIEW $\backslash v i . l i b \backslash U$ tility $\backslash$ file.llb $\backslash$ Read From Spreadsheet

File.vi 


\section{APPENDIX B - CORRELATED MODE PAIRS}

This appendix shows the mode shapes of remaining correlated mode pairs between the original FE model and the experimentally obtained mode shapes. The mode shapes of the first two correlated mode pairs are shown in Chapter 5.
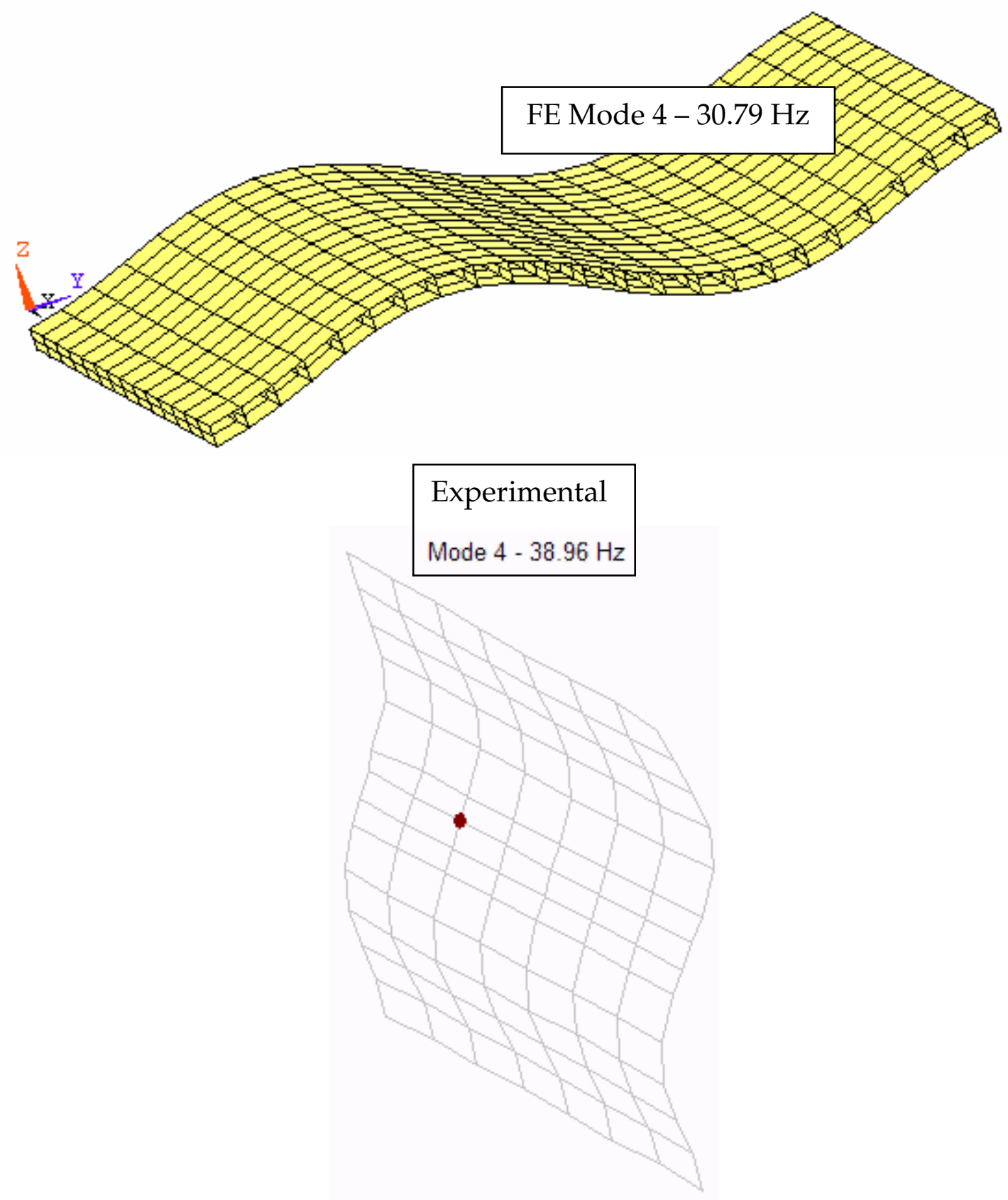


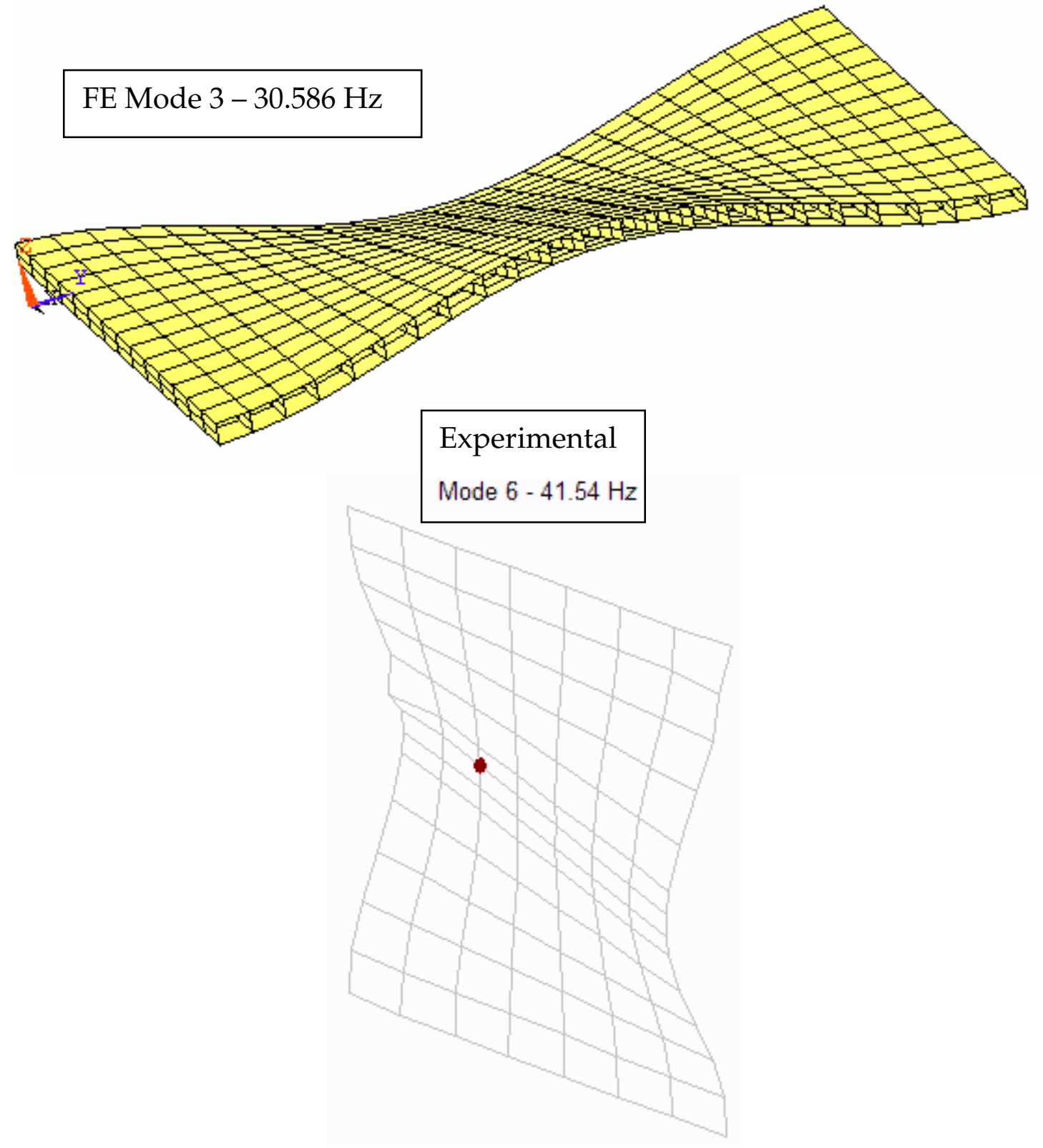




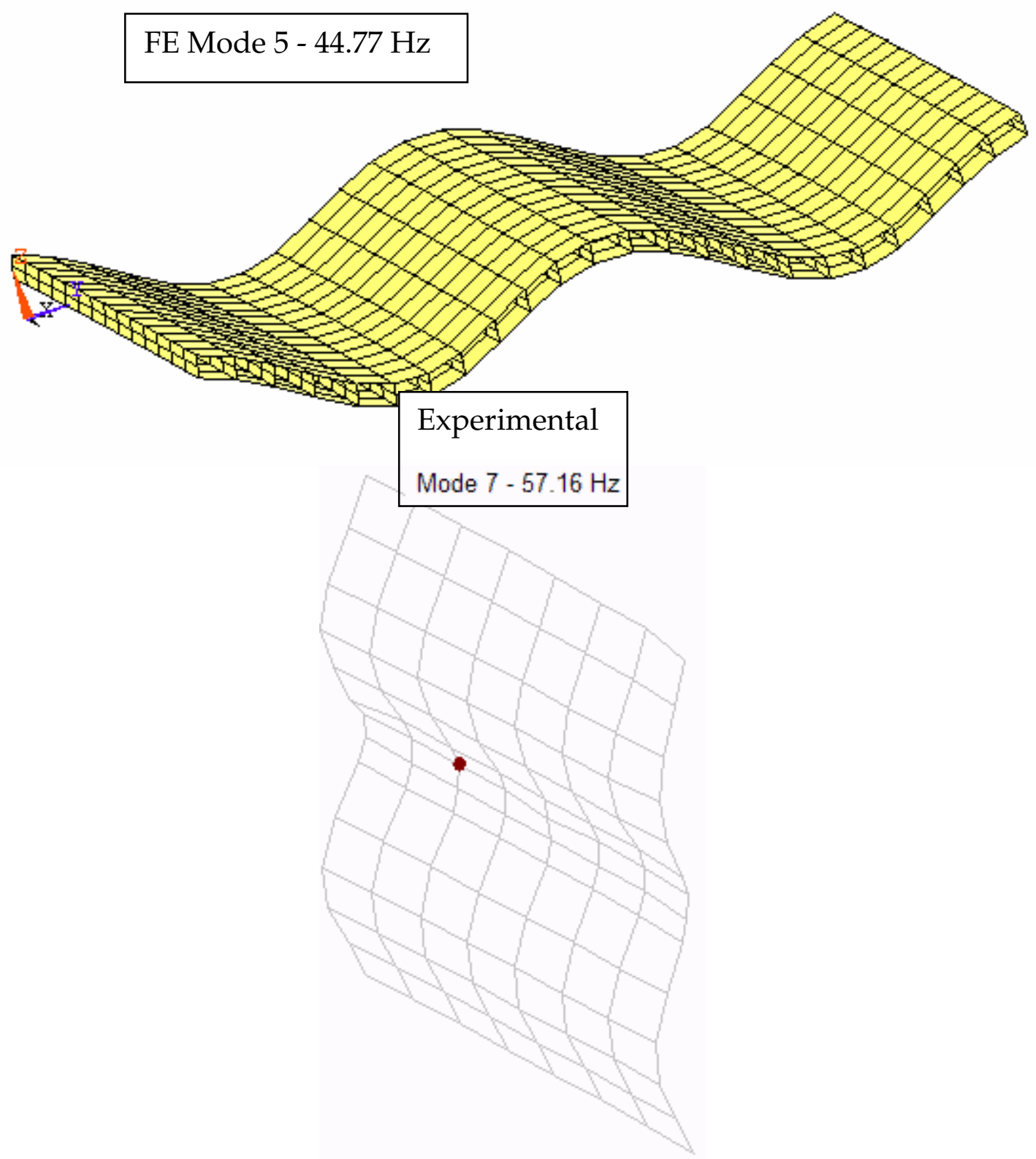



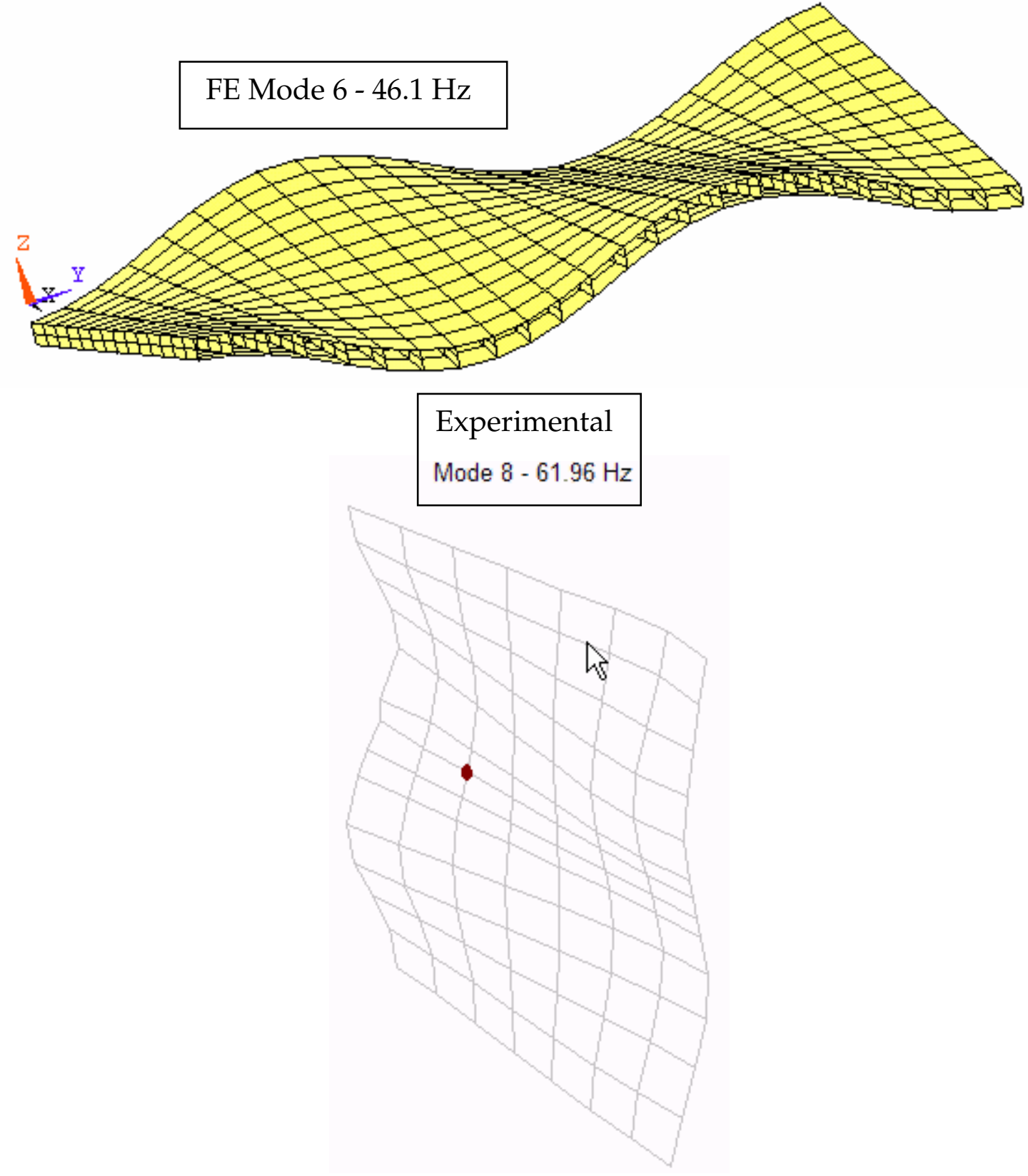


\section{UNCORRELATED MODES FROM EXPERIMENT}
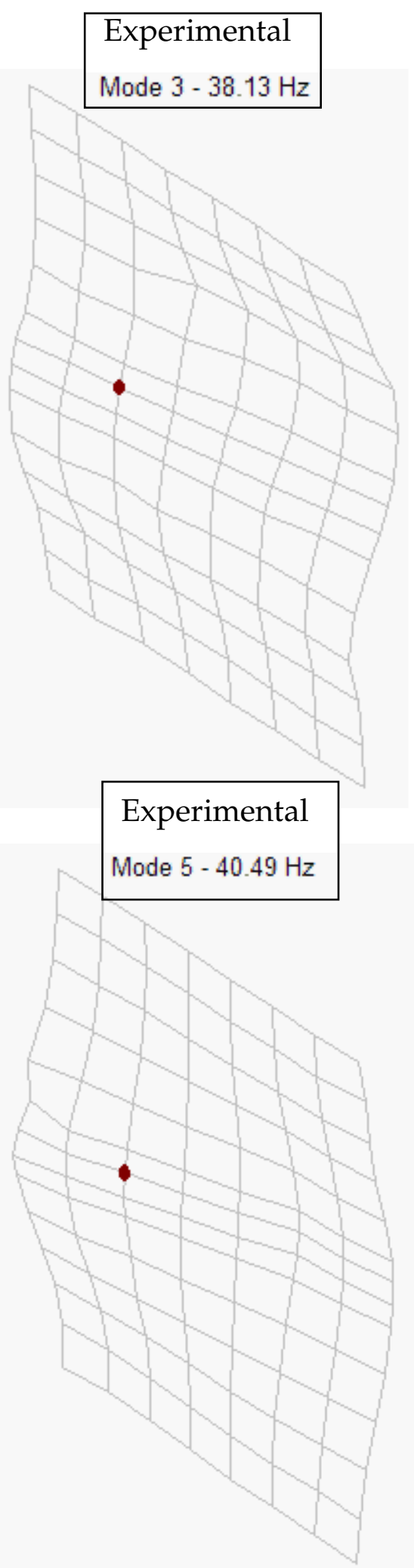